\title{
Ovarian cancer molecular pathology
}

\author{
Rémi Longuespée • C. Boyon • Annie Desmons • \\ Denis Vinatier • Eric Leblanc • Isabelle Farré • \\ Maxence Wisztorski • Kévin Ly • François D'Anjou • \\ Robert Day • Isabelle Fournier • Michel Salzet
}

Published online: 23 June 2012

(C) Springer Science+Business Media, LLC 2012

\begin{abstract}
Ovarian cancer (OVC) is the fourth leading cause of cancer mortality among women in Europe and the United States. Its early detection is difficult due to the lack of specificity of clinical symptoms. Unfortunately, late diagnosis is a major contributor to the poor survival rates for $\mathrm{OVC}$, which can be attributed to the lack of specific sets of markers. Aside from patients sharing a strong family history of ovarian and breast cancer, including the BRCA1 and BRCA2 tumor suppressor genes mutations, the most used biomarker is the Cancer-antigen 125 (CA-125). CA-125 has a sensitivity of $80 \%$ and a specificity of $97 \%$ in epithelial cancer (stage III or IV). However, its sensitivity is $30 \%$ in stage I cancer, as its increase is linked to several physiological
\end{abstract}

R. Longuespée $\cdot$ C. Boyon - A. Desmons · D. Vinatier ·

E. Leblanc $\cdot$ I. Farré $\cdot$ M. Wisztorski $\cdot$ I. Fournier $(\square) \cdot$

M. Salzet $(\square)$

Laboratoire de Spectrométrie de Masse Biologique Fondamentale et Appliquée, Université Nord de France,

EA 4550, Université de Lille 1, Cité Scientifique,

59650 Villeneuve D'Ascq, France

e-mail: Isabelle.fournier@univ-lille1.fr

e-mail: Michel.salzet@univ-lille1.fr

C. Boyon - D. Vinatier

Hôpital Jeanne de Flandre, service de Chirurgie Gynécologique,

CHRU Lille,

59037 Lille Cedex, France

R. Longuespée $\cdot$ E. Leblanc $\cdot$ I. Farré

Cancer Center-Centre Oscar Lambret,

3 rue Frédéric Combemale, BP 307, 59020 Lille Cedex, France

K. Ly • F. D'Anjou • R. Day

Institut de pharmacologie de Sherbrooke, Université de

Sherbrooke,

Sherbrooke, GC J1H 5N4, Canada phenomena and benign situations. CA-125 is particularly useful for at-risk population diagnosis and to assess response to treatment. It is clear that alone, CA-125 is inadequate as a biomarker for OVC diagnosis. There is an unmet need to identify additional biomarkers. Novel and more sensitive proteomic strategies such as MALDI mass spectrometry imaging studies are well suited to identify better markers for both diagnosis and prognosis. In the present review, we will focus on such proteomic strategies in regards to OVC signaling pathways, OVC development and escape from the immune response.

Keywords Ovarian cancer · Molecular pathology · Cancer antigen $\cdot$ MALDI imaging $\cdot$ Signaling pathway Immuno-oncology

\section{Introduction}

Age, genetic profile, hormonal profile (early onset of menses, high number of ovulatory cycles, late menopause, infertility, endometriosis), environmental factors (e.g., diet, obesity, smoking, virus), geographical areas, the racial and ethnic variation (correlated with the genetic inheritance) are all factors that have been implicated in OVC development $([1,2]) ;[3,4]$.; [5] Only $5-10 \%$ of OVC is hereditary [6]. In this context, CA-125 is insufficient as a single biomarker for OVC diagnosis [7]. OVC etiology is multiple, thus, like finding a needle in a haystack, identifying and validating a single specific biomarker appears to be a very low probability event. There is an unmet medical need to aid in screening and diagnosis, and thus alternative strategies need to be considered. 


\section{OVC signaling pathways}

Major intracellular signaling pathways are involved in OVC cell development. The understanding of the malignant mechanisms and the transformation of ovary cells to epithelial OVC are seen as a path to identify specific OVC biomarkers. The genetic studies reflect that OVC polymorphisms are highly unstable [8]. In fact, genic amplification, mutations, hypermethylations, and numerous chromosomal deletions have been found in OVC pointing the identification of several main categories of genes involved in OVC development such as tumor suppressor genes and oncogenes (Table 1) [6,9-12]. Thus, these genes are directly linked to cell signaling pathways, which play a central role in cancer cell growth, survival, invasion, and metastasis [13]. Discovering the "circuit maps" of these signaling pathways in OVC seems a good challenge for detecting novel therapeutic strategies [14-16]. According to literature, the signaling pathways associated with OVC are the followings: the nuclear factor kappa-light-chain-enhancer of activated B cells (NF-kB) pathway, the activator of transcription 3 (Jak-STAT 3) pathway, the mitogen-activated protein kinase (MAPK) pathway, the proto-oncogene tyrosineprotein kinase Src pathway, the ErbB activation pathway, the lysophosphatidic acid (LPA) pathway, the phosphatidylinositol 3-kinases (PI3K) pathway, the Mullerian inhibitory substance receptor pathway, the EGF and VGEF pathways and the ER beta pathway [17-40].

\subsection{Nuclear factor kappa-light-chain-enhancer of activated B cells pathway}

A correlation has been demonstrated between nuclear factor kappa-light-chain-enhancer of activated B cells (NF-KB) activation and $\mathrm{OVC}$ clinical profile showing that the expression of NF-kB p65 in OVC tumors is mainly nuclear and that their levels correlate with poor differentiation and late FIGO stage [41]. Positive patients for NF-kB p65 subunit staining had lower cumulative survival rates and lower median survival (20\% and 24 months, respectively) than negative patients $(46.2 \%$ and 39 months, respectively). Recently, microRNA-9 (miR-9) has been shown to downregulate the levels of NF-kB1 [42]. Moreover, results from gene expression microarray, using the highly specific IKK $\beta$ small-molecule inhibitor ML120b or IKK $\beta$ siRNA to decrease IKK $\beta$ expression, showed that IKK $\beta-N F-K B$ pathway controls genes associated with OVC cell proliferation, adhesion, invasion, angiogenesis, and the creation of a proinflammatory microenvironment. The NF- $\mathrm{BB}$ family proteins are implicated in signaling pathways driving tumor development and progression by activating anti-apoptotic genes. It also activates genes involved in cell cycle progression and the secretion of tumor necrosis factor (TNF) $\alpha$, interleukin (IL)-6, and growth hormones. Moreover, NF-kB regulates genes promoting pro-angiogenic environment through enhanced production of IL-8 and vascular endothelial growth factor and creation of a microenvironment that may prevent immune surveillance [43-45].

\subsection{The mitogen-activated protein kinase pathway}

Previous studies identified that mitogen-activated protein kinase (MAPK) pathway is activated in OVC (ref). The downregulation of CL100, an endogenous dual-specificity phosphatase known to inhibit MAPK, plays a role in progression of human OVC by promoting MAPK pathway [46]. OVC epithelial cells display 10-25 times less activity of C100 compared to normal ovarian epithelial cells. The MEK inhibitor PD98059 sensitized OVC cell lines to Cisplatin. Upregulation of CL100 in ovarian cancer cells decreases adherent and non-adherent cells growth and induces phenotypic changes, including loss of filopodia and lamellipodia in association to decreased cell motility [46]. Thus, the development of specific MAPK pathway inhibitors is currently in process [47].

\subsection{The ErbB activation pathway}

Overexpression of c-erbB-2 protein in tumors has been reported from approximately $25 \%$ of patients with epithelial OVC $[48,49]$. Multivariate analysis showed that c-erbB-2 overexpression and residual tumors, greater than $2 \mathrm{~cm}$, decrease survival rates $[48,49]$.

\subsection{The Mullerian inhibitory substance receptor pathway}

Anti-Müllerian hormone (AMH) is a member of the transforming growth factor $\beta$ (TGF- $\beta$ ) family In absence of AMH, Müllerian ducts of both sexes develop into uterus, Fallopian tubes, and the upper part of the vagina. Also, AMH exerts inhibitory effects on the differentiation and steroidogenesis of the immature ovaries, the follicle of adult ovaries and as well as fetal and postnatal Leydig cells. Other proposed targets of AMH actions include breast, prostate, ovarian, and uterine cancer cells [50].

\subsection{Lysophosphatidic acid signaling pathway}

Lysophosphatidic acid (LPA) is generated through hydrolysis of lysophosphatidyl choline by lysophospholipase D/autotaxin or via hydrolysis of phosphatidic acid by phospholipase $\mathrm{A}_{2}$ or $\mathrm{A}_{1}$. LPA is a ligand for at least four different heptahelical transmembrane $\mathrm{G}$ protein-coupled receptors (GPCR; $\mathrm{LPA}_{1} /$ endothelial differentiation gene (Edg)2, $\mathrm{LPA}_{2} / \mathrm{Edg} 4, \mathrm{LPA}_{3} /$ $\mathrm{Edg} 7$, and $\mathrm{LPA}_{4} / \mathrm{GPR} 23 / \mathrm{P}_{2} \mathrm{Y}_{9}$ ) results in activation of at least three distinct $G$ protein subfamilies $\left(\mathrm{G}_{\mathrm{q}}, \mathrm{G}_{\mathrm{i}}, \mathrm{G}_{12 / 13}\right)$ and initiation of multiple signaling pathways, including Ras/ 
Raf/mitogen-activated protein kinase, phosphoinositide3-kinase/Akt, phospholipase $\mathrm{C}$ /protein kinase $\mathrm{C}$, or RhoA small GTPase signaling [51]. Activation of these G-proteins stimulates release of cell surface metalloproteases, like the ADAM family, inducing subsequently cleavage of EGF-like ligand precursors and thus EGFR (HER/erbB) family of. This transactivation process seems to involve many signaling pathways, e.g., mitogen-activated protein kinase (p38 and p44/42), protein kinase C or c-Src. LPA induces cancer cell proliferation, survival, drug resistance, invasion, opening of intercellular tight junctions and gap junction closure, cell migration, or metastasis [51].

\subsection{Phosphatidylinositol 3-kinases pathway}

The phosphoinositide 3-kinase (PI3K)/AKT pathway is a key component of cell survival and is implicated in OVC cell motility, adhesion, and contributes to metastatic/invasive phenotypes of various cancer cells. PI3K was also reported to be involved in cell growth and transformation. Its effect is related to indirect or direct deregulation of its signaling pathway and causes aberrant cell-cycle progression and transformation of normal cells into tumor cells. Due to hyperactivation of the PI3K/Akt pathway in many cancers and its role in multiple aspects of cancer progression, inhibition of the PI3K/Akt signaling pathway has been investigated as a treatment for cancer [52]. A proof of concept is based on the loss of function of inositol polyphosphate 4-phosphatase type II (INPP4B) from the PI3K/ Akt pathway acting as a tumor suppressor. Remarkably, loss of INPP4B in ovarian cancer correlates with poor patient outcomes [52].

\subsection{Estrogen receptors pathway}

The mitogenic action of estrogen seems to be critical to the etiology and progression of human gynecologic cancers $[53,54]$. Estrogens influence the growth, differentiation, and function of reproductive tissues by interacting with their receptors to mediate various signaling pathways associated with the risk of ovarian cancer $[53,54]$. Estrogen receptors exist in two forms, estrogen receptor alpha $(\mathrm{ER} \alpha)$ and estrogen receptor beta $(\operatorname{ER} \beta)$ which is the predominant estrogen receptor in the ovaries [26]. Recent in vivo and in vitro studies suggest that $\mathrm{ER} \beta$ is involved with the control of cellular proliferation, motility and apoptosis in ovarian cancer; and loss of ER $\beta$ expression is associated with tumor progression $[55,56]$.

Taken together, the above studies reveal that all these signaling pathways are implicated in OVC cell differentiation, cell movement and apoptosis, and are directly linked to OVC tumor suppressor genes and oncogenes (Table 1). At this moment, it is relevant to establish a link between these signaling pathways and proteins specific to OVC cells previously identified by classical proteomic studies or mass spectrometry imaging (MSI).

\section{Proteomic studies}

Since the last decade, proteomic studies have been widely used to identify key proteins implicated in different ovarian cancer processes. Using these new technologies, many authors identified panels of biomarkers and tested these for their relevant utility to screen early stages of the disease. Candidate biomarkers have been detected in serum or tissues using SELDI chips analysis. From this method, a biomarker, the alpha chain of haptoglobulin, has been identified and found in higher levels in samples from OVC patient [57]. Then, a protein pattern has been determined by Yu et al. [58] with $96.7 \%$ specificity, $96.7 \%$ sensitivity, and a predictive positive value of $96.7 \%$. Another group reported the use of the following markers: transthyretin, beta-hemoglobin, apolipoprotein A1, and when used in combination with $\mathrm{CA} 125$, has been found to have a ROC of 0,959 for the detection of ovarian cancer, when CA 125 used alone 0.613 [59]. Two separate classical proteomic studies in 2006 [60] and 2008 [61], using liquid chromatography (LC) separation followed by MS (LC-MS), have shown that early and late stage endometroid ovarian carcinoma MS profiles can be distinguished using a clustering analysis, which separates profiles based on feature similarity; in

Table 1 The genetic polymorphism of the OVC

\begin{tabular}{|c|c|c|c|c|}
\hline \multirow[t]{2}{*}{ Gene classification } & \multicolumn{2}{|l|}{ Tumors suppressors } & \multicolumn{2}{|l|}{ Oncogenes } \\
\hline & \multicolumn{2}{|c|}{$\begin{array}{l}\text { ARHI, RASSF1A, DLEC1, SPARC, DAB2, } \\
\text { PLAGL1, RPS6KA2, PTEN, OPCML, BRCA2, } \\
\text { ARL11, WWOX, TP53, DPH1, BRCA1, PEG3 }\end{array}$} & \multicolumn{2}{|c|}{$\begin{array}{l}\text { RAB25, EVI1, EIF5A2, PRKCI, PIK3CA, } \\
\text { MYK, EGFR, NOTCH3, KRAS, ERBB2, } \\
\text { PIK3R1, CCNE1, AKT2, AURKA }\end{array}$} \\
\hline Gene modulation & Amplification & Mutation & Hypermethylation & Deletion \\
\hline Activation & $\begin{array}{l}\text { RAB25, PRKCI, EVI1 and } \\
\text { PIK3CA, FGF1, MYC, } \\
\text { PIK3R1 and AKT2, AURKA }\end{array}$ & $\begin{array}{l}\text { KRAS, BRAF, CITNNB1, } \\
\text { CDKN2A, APC, PIK3CA, } \\
\text { KIT, SMAD4 }\end{array}$ & IGF2, SAT2 & \\
\hline Deletion & & $\begin{array}{l}\text { BRCA1, BRCA2, } \\
\text { PTEN, TP53 }\end{array}$ & $\begin{array}{l}\text { MUC2, PEG3, MLH1, } \\
\text { ICAM1, PLAGL1, ARH1 }\end{array}$ & $\begin{array}{l}\text { BRCA1, BRCA2, PTEN, } \\
\text { TP53, PEG3, PLAGL1, ARH }\end{array}$ \\
\hline
\end{tabular}


this case, similar protein masses. These studies demonstrate that "classical" proteomics can generate molecular fingerprints of a disease. However, the disadvantage of this method is the loss of molecular discrimination of tissues subtypes regarding the anatomical context. This effect can be seen in heterogeneous carcinomas where different structural elements express specific proteome. Laser capture micro-dissection (LCM) is one of the techniques used to solve this problem/ inconvenient, but this method is time consuming and based on cells phenotypes rather than the molecular content of the cells. MALDI mass spectrometry imaging (MSI) keeps the spatial localization of the markers and discriminates cells to theirs molecular content. Using this technology, our group has been able to discriminate several novel biomarkers in ovarian cancer (Fig. $3[62,63]$ ) e.g., the C-terminal fragment of the immunoproteasome 11S, Reg alpha or mucin 9. In 2010, Hoffmann's team was able to identify 67 proteins, using this technology on formalin-fixed paraffin-embedded (FFPE) archived ovarian tissue $[64,65]$. In sum, proteomic studies performed at the level of the serum, ascites, and tissues have also clearly shown the presence of protein associated the intracellular signaling pathways activation, i.e., protein associated with cell proliferation, signaling to skeleton, invasion, resistance (Table 2).

\subsection{Proteins associated with cell proliferation}

The protein family S100 has been previously detected in aggressive ovarian tumors [66] and more specifically, S100 A11 and S100 A12 proteins have been identified by MALDI-MSI [67]. S100 A11 has been detected in ovarian ascites [68] and this protein (or calgizzarin) is known to regulate cell growth through the inhibition of DNA synthesis $[69,70]$. S100 A12 is known to promote leukocyte migration in chronic inflammatory responses [71]. The expression of oviduct-specific glycoprotein (OGP, Mucin-9), a marker of normal oviductal epithelium has also been reported in conjunction with S100 proteins and cytoskeleton modifying proteins [67]. Supportive data were provided by Woo and associates who found that OGP is a tubal differentiation marker and may indicate early events in ovarian carcinogenesis. These data also support the hypothesis, recently reported, of oviduct ascini as the origin of serous ovarian carcinoma [1]. From immune components, stromal cellderived factor-1 (SDF-1), induces proliferation in OVC by increasing the phosphorylation and activation of extracellular signal-regulated kinases (ERK)1/2, which correlates to epidermal growth factor (EGF) receptor transactivation. Similarly, TGF- $\beta$ produced by Treg cells stimulates tumor cell proliferation, increases matrix metalloproteinase's (MMP) production, and enhances invasiveness of OVC cells [72-76]. In OVC, IL7 has been found in ascites and plasma, and it's acting as a growth factor like in breast cancer [77-79].
Table 2 Biomarkers identified by genomic, classical proteomic, or MSI approaches

\begin{tabular}{|c|c|}
\hline & Genomic \\
\hline \multicolumn{2}{|l|}{ Marker name } \\
\hline Mesothelin-MUC16 & [192] \\
\hline STAT3 & [192] \\
\hline $\begin{array}{l}\text { LPAAT- } \beta \text { (lysophosphatidic } \\
\text { acid acetyl transferase beta) }\end{array}$ & [193] \\
\hline Inhibin & [194] \\
\hline Kallikrein Family $[9,11,13,14]$ & [195] \\
\hline Tu M2-PK & [196] \\
\hline$c$-MET & [197-199] \\
\hline $\begin{array}{l}\text { MMP-2, MMP-9, MT1-MPP: } \\
\text { matrix metalloproteinase }\end{array}$ & {$[158,200,201]$} \\
\hline EphA2 & [202-204] \\
\hline $\begin{array}{l}\text { PDEF (prostate-derived } \\
\text { Ets factor) }\end{array}$ & {$[116,205]$} \\
\hline IL-13 & {$[177]$} \\
\hline $\begin{array}{l}\text { MIF (macrophage inhibiting } \\
\text { factor) }\end{array}$ & {$[116,205]$} \\
\hline $\begin{array}{l}\text { NGAL (neutrophil gelatinase- } \\
\text { associated lipocalin) }\end{array}$ & {$[206]$} \\
\hline CD46 & [207-209] \\
\hline $\begin{array}{l}\text { RCAS } 1 \text { (Receptor-binding } \\
\text { cancer antigen expressed } \\
\text { on SiSo cells) }\end{array}$ & {$[117,210]$} \\
\hline Annexin 3 & [211] \\
\hline Destrin & {$[212,213]$} \\
\hline
\end{tabular}

Cofilin-1

GSTO1-1

[212,213]

[212,213]

[215]

[216,217]

[211]

[218]

[219]

[220]

$78 \mathrm{kDa}$

glucose-regulated

Protein

Calreticulin

[220]

Endoplasmic

reticulum protein ERp29

Endoplasmin

Protein disulfideisomerase

A3

Actin, cytoplasmic 1

Macrophage

Tropomyosin

imaging

Actin, cytoplasmic 2

capping protein

alpha 3 chain, alpha- 4 chain

Vimentin

[220]

[67] 
Table 2 (continued)

Genomic Proteomic $\begin{aligned} & \text { MALDI } \\ & \text { imaging }\end{aligned}$

1(VI) chain

Dihydrolipoyllysineresidue

succinyltransferase

component of 2-oxoglutarate

Dehydrogenase

Pyruvate

dehydrogenase E1

component beta

Superoxide

dismutase [Cu-Zn]

Chromobox protein

homologue 5

Lamin B1, B2

14-3-3 protein

Cathepsin B

Heterogeneous

nuclear

ribonucleoprotein $\mathrm{K}$

Nucleophosmin

Peroxiredoxin 2

Prohibitin

Receptor

tyrosine-protein

kinase erbB-3

Fibrinogen gamma

Chain

Splicing factor, arginine/

serine-rich 5

Elongation factor

1-beta

Lysosomal protective protein

Hemoglobin beta

subunit

Transitional endoplasmic

reticulum ATPase

Serum albumin

Protein KIAA0586

Similar to testis expressed

sequence $13 \mathrm{~A}$

SNRPF protein

Fibrinogen gamma chain

Transitional endoplasmic

reticulum ATPase

Heat shock $70 \mathrm{kDa}$ protein

$1,60 \mathrm{~K}$ protein

Heterogeneous nuclear

ribonucleoprotein $\mathrm{K}$

Keratin, type I cytoskeletal

7, 9, 18, 19 ?

Adenylosuccinate Lyase
Table 2 (continued)

Genomic Proteomic MALDI

imaging

Peroxiredoxin 2

Glutathione $S$-transferase P

Ras-related protein

Rab-7

Prohibitin

Cathepsin B

Heterogeneous nuclear

ribonucleoprotein $\mathrm{K}$

Tumor protein D54

Rho GDPdissociation

inhibitor 1

Annexin A2

ATP synthase beta Chain

Heterogeneous nuclear ribonucleoprotein $\mathrm{K}$

Actin, cytoplasmic 1

Heterogeneous nuclear

ribonucleoprotein $\mathrm{A} / \mathrm{B}$

Immunoprotease activator

fragment $11 \mathrm{~S}$

Mucin-9

S100-A11

Apolipoprotein A1

Prolargin

Lumican Precursor

Siderophilin

Alpha 1 antiprotease

Phosphatidyl Ethanolamine

Binding Protein

Hemopexin

Profilin -1

HLA G

Chorionic Gonadotropin

Hormone
pDcs are also present in tumor environment and stimulate tumor growth by releasing TNF- $\alpha$ and IL8. The sum of these data reflects that cytokines exert pleiotropic effects in OVC and exert a major role in tumor proliferation.

\subsection{Signaling to the cytoskeleton}

Several candidate proteins, including profilin-1, cofilin-1, vimentin, and cytokeratin 19 are involved in the intracellular 
signaling to the cytoskeleton. Changes in cell phenotypes, such as the conversion of epithelial cells to mesenchymal cells, are integral, not only to embryonic development, but also to cancer invasion and metastasis. Cells undergoing epithelial-mesenchymal transition (EMT) lose their epithelial morphology, reorganize their cytoskeleton, and acquire a motile phenotype through the up- and downregulation of several molecules, including tight and adherent junction proteins and mesenchymal markers. TGF- $\beta$ has been described to induce EMT in ovarian adenosarcoma cells [80]. In the human lung adenocarcinoma cell line A549, this differentiation is followed by modification in the expression of several cytoskeleton proteins including $\beta$-actin, cofilin 1 , moesin, filamin A and B, heat-shock protein beta-1, transgelin-2, S100 A11, and calpactin. Most likely, these changes increase migratory and invasive abilities [81]. Treatment of the OVC cell line SKOV-3 with TGF- $\beta$ increases the expression of cofilin and profilin-1 at mRNA and protein levels and modifies its cytoskeletal organization assessed by confocal microscopy analysis [76]. After binding to its receptor, TGF- $\beta$ stimulates the reorganization of the actin cytoskeleton and triggers the formation of stress fibers and cellular protrusions [82].

\subsection{Hormonal pathways}

Several hormones have been detected during proteomic studies like leptin, prolactin, osteopontin, insulin-like growth factor-II, anti-mullerian hormone, and HCG [83]. Leptin is produced by adipocytes and known to stimulate the growth of BG-1 ovarian cancer cells via the extracellular signal-regulated kinase signaling pathway. Recent studies have demonstrated the involvement of the estrogen receptor (ER) pathway in the mechanism of leptin-induced OVC growth via STAT-3 [84]. Elevated seric levels of prolactin (PRL) in ovarian and endometrial cancers have been reported, indicating a potential role for PRL in carcinogenesis [85]. Binding of PRL to its receptor was followed by rapid phosphorylation of extracellular signal-regulated kinase (ERK) $1 / 2$, mitogen-activated protein kinase/ERK kinase 1, signal transducer and activator of transcription 3, CREB, ATF-2, and p53 and activation of 37 transcription factors in ovarian and endometrial carcinoma cells. Osteopontin (OPN) is known to increase the survival of OVC under stress conditions in vitro and promotes the late progression of ovarian cancer in vivo. The survival-promoting functions of OPN are mediated through Akt activation and the induction of HIF-1alpha expression [86]. Insulin-like growth factor binding protein 2 (IGFBP2) is also overexpressed in ovarian malignant tissues and in the serum and cystic fluid of ovarian cancer patients, suggesting its important role in the biology of ovarian cancer by increasing invasion capability of ovarian cancer cells [87]. HCG is a glycoprotein consisting of subunits alpha and beta, which are non convalently linked. The hormone is normally produced by the syncytiotrophoblastic cells of the placenta and is elevated during pregnancy. Recently, beta-hCG and alpha-fetoprotein have been detected in OVC germ cell tumors $[88,89]$. These proteins have been detected at early stages of the cancer, as well as lysophosphatidic acid, mesothelin, HE4, osteopontin, VEGF, IL-8, M-CSF, different kallikreins [90-92], and the Cterminal fragment of the $11 \mathrm{~S}$ immunoproteasome (Reg-alpha) $[1,67]$.

Most of the above proteins are directly linked to signaling pathways for cytoskeleton remodeling, contractility, junction remodeling, adhesion, invasion, migration, cell cycle progression, proliferation, metastasis, apoptosis/necrosis, angiogenesis, endothelial permeability, vascular remodeling, metalloprotease activation, and EGFR transactivation (Fig. 1). The immune response modulation is another dysregulated cell signaling pathway found in OVC. In fact, cancer cells use various strategies to escape from the immune response. In this context, it is interesting to link activated intracellular signaling pathways to the proteins involved in immune response escape.

\subsection{Proteins involved in immune response modulation}

Several hepatic and acute phase proteins (haptoglobin- $\alpha$, bikunin, C-reactive protein), cytokines and growth factors (vascular endothelial growth factor-VEGF, insulin-like growth factor II-ILGF II, IL-6, IL-10, macrophagecolony stimulating factor-M-CSF, osteopontin, macrophage inhibitory factor) have been detected in OVC. However, recent studies have shown that ovarian cancerassociated ascites may provide an immunosuppressive environment [77]. A high CD4/CD8 ratio, which may indicate the presence of regulatory $\mathrm{T}$ cells, is associated with poor outcomes. Recently, Clarke et al. [93] have validated in a cohort of 500 ovarian cancer patients that the presence of intraepithelial CD8+ T cells correlates with improved clinical outcomes for all stages of the diseases. Curiel et al. [94] demonstrated in 104 ovarian cancer patients that CD4+ CD25+FoxP3+Tregs suppress tumor-specific T cell immunity and contributes to growth of the tumor in vivo. These data suggest a mechanism of immune suppression in ovarian cancer either through overexpression of Tregs or by the capability of tumors to escape from the immune response (using molecular mimicry) or immunosurveillance $[95,96]$. Additional evidences have reinforced the involvement of Tregs in ovarian cancer. CCL22, a protein secreted by dendritic cells and macrophages, highly expressed in tumor ascites is known to have a role in Treg cell migration in tumors [94]. Overexpression of the immunoregulatory enzyme indoleamine 2,3-dioxygenase (IDO) has also been demonstrated in ovarian cancer [97-100]. IDO suppresses 
Fig. 1 Ovarian cancer intracellular signaling pathways scheme. LPA/hormones bind to RPCG receptors. Cytokines/ growth factors bind RTK receptors. Intracellular pathways and signaling out are detailed. Cellular output after signaling pathways activation are presented

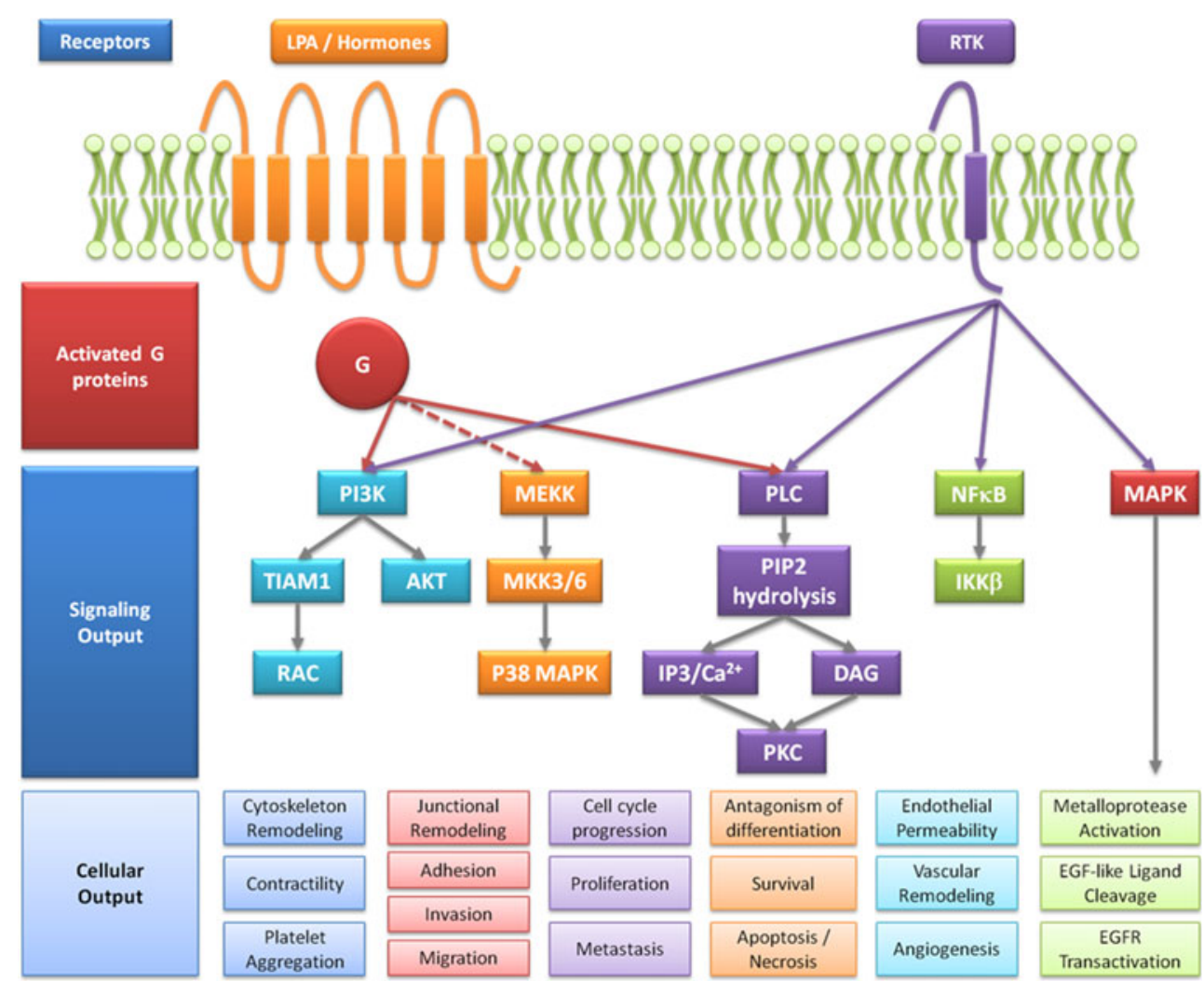

the proliferation of effector T cells or natural killer cells and their killer functions $[98,101]$. In ovarian cancer, high IDO expression in tumor cells was correlated with a reduced number of tumor-infiltrating lymphocytes [97]. Reduced IL- 2 combined to elevated TGF- $\beta$ and IL-10 levels favor induced Tregs [102]. On the other hand, tumor cells escape the immune response by inducing peripheral mature DCs to induce IL-10 CCR7+CD45RO+CD8+Tregs. Primary suppressive $\mathrm{CCR} 7+\mathrm{CD} 45 \mathrm{RO}+\mathrm{CD} 8+\mathrm{T}$ cells are found in the tumor environment of patients with ovarian cancer [103]. Another way that tumor cells escape immunosurveillance is through the expression of human leukocyte antigen (HLAG) ([104-106] \{Sheu, 2007 \#5782). Recent studies have shown that the expression of HLA-G was detected in 22/ $33(66.7 \%)$ primary tumor tissues but was absent in normal ovarian tissues $(P<0.01)$. Cytotoxicity studies showed that HLA-G expression dramatically inhibits cell lyses by NK92 cells $(P<0.01)$, which could be restored by the antiHLA-G conformational mAb $87 \mathrm{G}(P<0.01)$. HLGA-G5 type has been detected in tumor while soluble form of HLA-G was found in ascites $[107,108]$ and in the blood of patients [109]. HLA-G seems to be implicated in the immune response modulation through NKT cell inhibition [110]. In the tumor cells expressing a B7 co-stimulatory family molecule, B7H4 is known to inhibit antigen-dependent induction of $\mathrm{T}$ cell proliferation and activation. B7-H4 promotes the malignant transformation of epithelial cells by protecting them from apoptosis and seems to be expressed at an early stage of tumor development [111-113]. In the same way, tumor cells highly express the mesothelin-Mucin 16 (MUC16), which inhibits the formation of immune synapses between NK cells and ovarian tumor targets [114] (Fig. 2).

Transcriptomic and proteomic studies performed at the tumor level confirmed the active role of the tumor cells to escape from the immune response. For example, the overexpression of the macrophage migration inhibitory factor (MIF) $[115,116]$ and the receptor-binding cancer antigen expressed on SiSo cells [117] (known to be implicated in lymphocytes apoptosis), were shown using transcriptomic approaches MIF contributes to the inhibition of antitumoral CD8+ T and NK cells by downregulating NKG2D levels (NK cell receptor NK group 2D). [118]. From MALDI-MSI studies, five factors involved in immune response modulation in mucinous tumors have been identified, namely a Cterminal fragment of the 11S immunoproteasome (Reg-alpha), orosomucoid, apolipoprotein A1, hemopexin, and lumican, which have also been detected in ascites $[62,63,67,119,120]$. Cleavage of PSME1 (proteasome activator complex subunit 1, $11 \mathrm{~S}$ regulator complex [syn: PA28 alpha]) into the Reg-alpha fragment could lead to default self-antigen presentation [62] (Fig. 3). PA28 is a regulatory complex associated with $20 \mathrm{~S}$ proteasome that consists of three subunits: alpha, beta, and gamma [121]. Binding of the $11 \mathrm{~S}$ regulator complex to the 20S proteasome does not depend on ATP hydrolysis and, unlike the 19S regulatory subunit, the 11S regulator complex does not catalyze degradation of large proteins. Rather, it is 


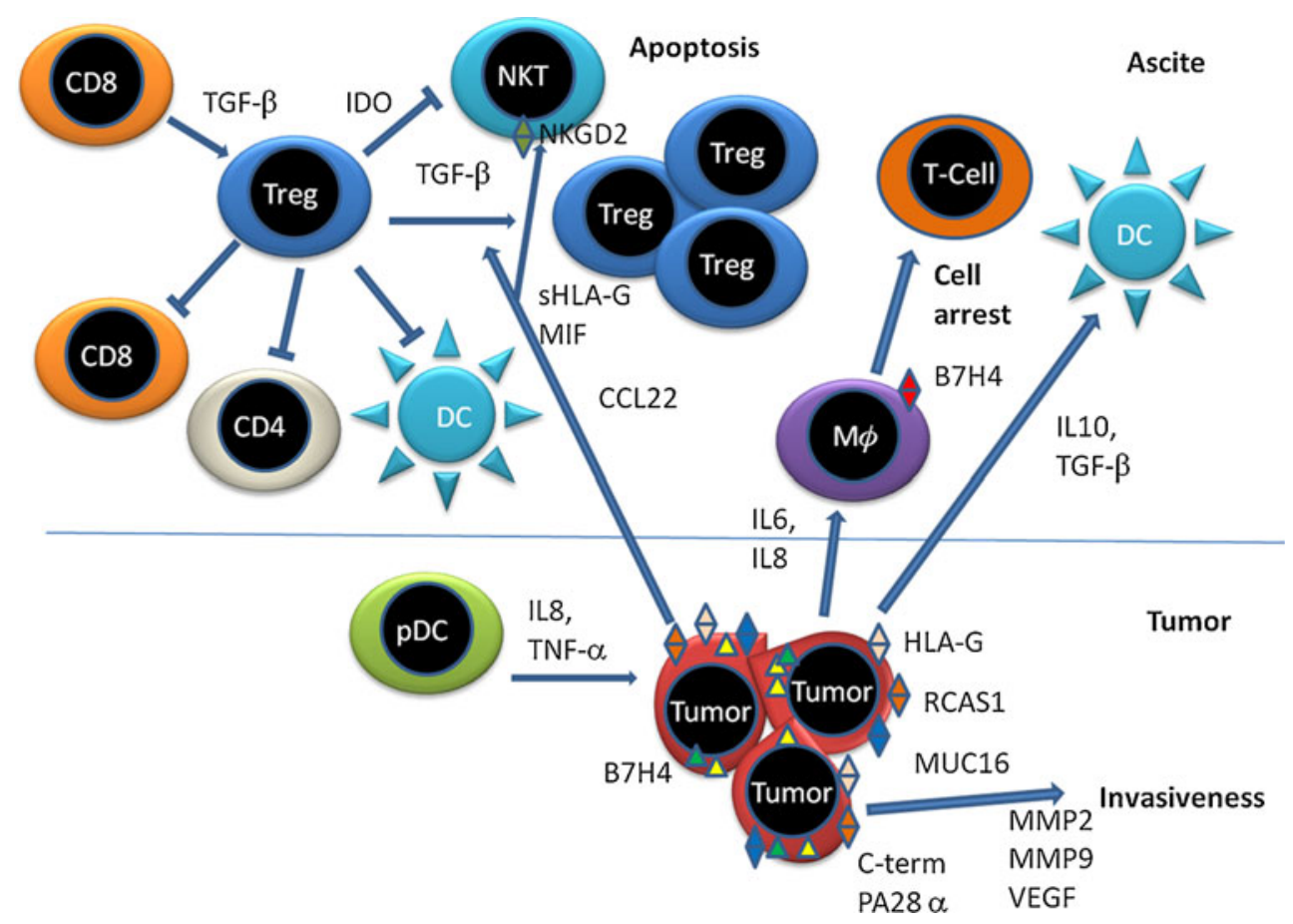

Fig. 2 Tumor cell factors production for escaping immune response. Apolipoprotein A1 has been detected in conjunction with transthyretin and transferrin in early-stage mucinous tumors. Lumican, which is a small LRR proteoglycan in the extracellular matrix is known to be overexpressed in breast cancer and to play a role in tumor progression. ApoA-I is known to decrease expression of surface molecules such as CD1a, CD80, CD86, and HLA-DR in dendritic cells, and it stimulates the production of IL-10. Hemopexin has recently been demonstrated to reduce TNF and IL-6 from macrophages during inflammation, and it limits TLR4 and TLR2 agonist-induced macrophage cytokine

responsible for MHC-class 1 antigen processing [122-124], which is greatly improved by interferon gamma-induced expression of the alpha and beta subunits [125]. Several viral proteins that interact with these proteasome subunits have been reported and may interfere with host anti-viral defenses, thereby contributing to cell transformation [126]. The manner in which they bind to the core particle (via its subunits C-terminal tails) and induce a $\alpha$-ring conformational change (to open the $20 \mathrm{~S}$ gate), suggests a mechanism similar to the 19S particle [121]. No role in ovarian cancer has been demonstrated for the $11 \mathrm{~S}$ regulator complex. Our data demonstrate a high expression level of PA28 in carcinomas, especially in epithelial cells at stage III/IV (Fig. 3a,b), also at early stages Ia (Fig. 3c) [1] and as a marker of tumor relapse after chemotherapy (Fig. 3d). The PA28 activator belongs to the antigen processing machinery (APM). Its alteration by cleavage in ovarian carcinomas may be a mechanism to evade immune recognition. Similar hypothesis has already been proposed in the case of APM chaperones such as TAP, LMP2, LMP10, and tapasin in colon carcinoma, small cell lung carcinoma, and pancreatic carcinoma cell lines. In fact, IFN- $\gamma$ treatment of these carcinoma cell lines corrects the TAP, LMP, and tapasin deficiencies and enhances PA28 $\alpha$, production. Orosomucoid have immunosuppressive properties in ovarian carcinoma ascites through inhibition of IL-2 secretion by lymphocytes. The tumor environment expresses molecules that can convert functional APCs into dysfunctional ones. These dysfunctional APCs in turn stimulate Treg differentiation and expansion. The tumor produces IL6, IL8, MUC18, MIF, RCAS1, sHLA-G exerting negative effects on the $T$ cells.PA28 activator belongs to the antigen processing machinery (APM). Its alteration by cleavage by (furin, PACE4) in ovarian carcinomas participates in a mechanism to evade immune recognition

LMP7, calnexin and calreticulin expression, which is accompanied by increased levels of MHC class 1 antigens [127]. PSEM2 (proteasome activator complex subunit 2, PA28 beta) has also been detected in ascites fluid, implicating an immune cell tolerance toward carcinoma cells and confirms the dysregulation of self-antigen processing in ovarian tumors [68]. Additionally, PA28 alpha seems to be a target for EpsteinBarr virus (EBV) and herpes virus (HV), as our proteomic and qPCR data indicates [128,129]. Pudney et al. [130] have also shown that as EBV-infected cells move through the lytic cycle, their susceptibility to EBV-specific $\mathrm{CD} 8^{+} \mathrm{T}$ cell recognition falls dramatically, concomitant with a reduction in transporter associated with antigen processing (TAP) function and surface human histocompatibility leukocyte antigen (HLA) class 1 expression. The implication of virus in the etiology of ovarian cancer is also sustained by the over-expression of furin enzyme [1,67], which is known to be implicated in glycoprotein $\mathrm{B}$ cleavage through a motif $\mathrm{R}-\mathrm{X}-\mathrm{K} / \mathrm{R}-\mathrm{R}$ in both $\mathrm{EBV}$ and HV $[128,129]$.

Among the other four factors that might participate in the tolerance phenomenon by inhibiting immune activation, the acute phase protein orosomucoid (ORM, also known as 

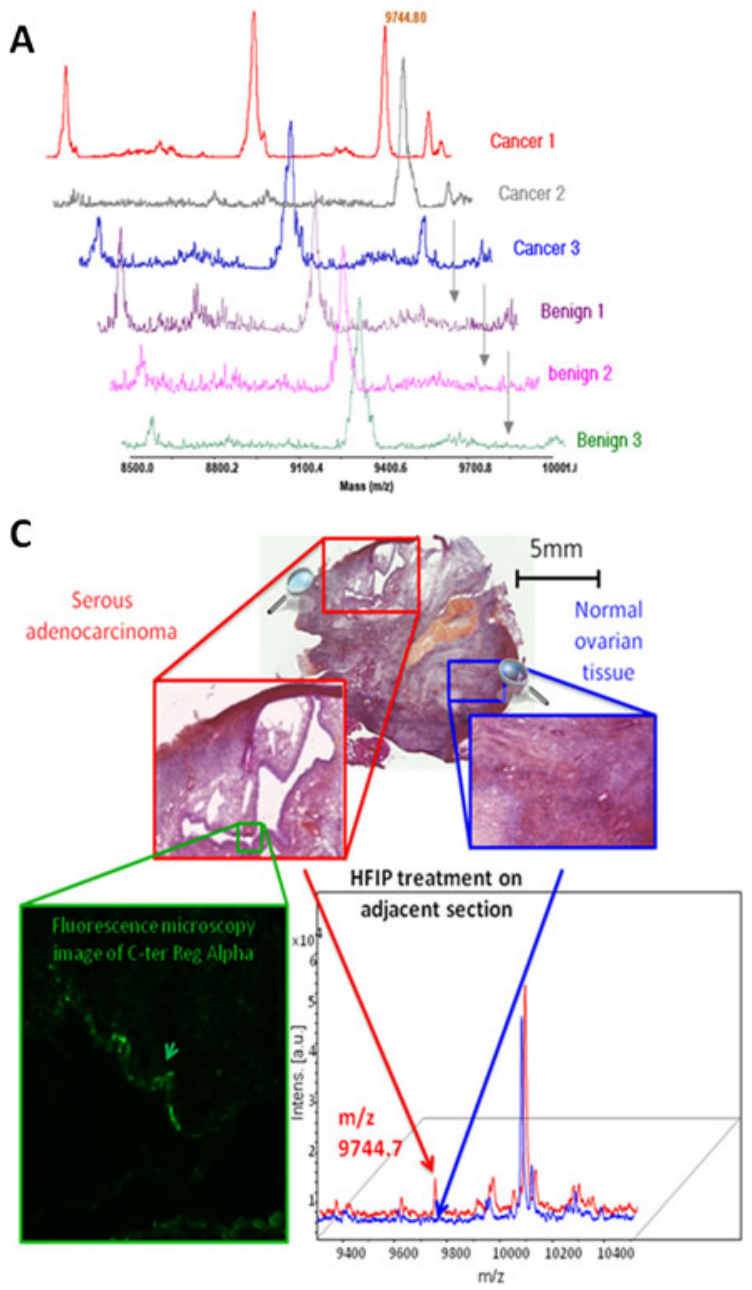

Fig. 3 Example of MALDI MSI and profiling workflow for ovarian cancer biomarker discovery and validation: a MALDI mass spectrometry profiling spectra of six patients, i.e., three suffering of adenocarcinoma and three benign tumors. The $\mathrm{m} / \mathrm{z}$ at 9744 corresponds to the Cter fragment of RegAlpha. b Epithelial ovarian cancer tissue section with a benign and a cancerous parts submitted to an automatic matrix deposition using a micro spotting machine (CHIP 1000, Shimadzu). Molecular image corresponding of the $\mathrm{m} / \mathrm{z} 9744$ Cter fragment of RegAlpha in the tumoral area of the ovarian biopsy with inset pictures of immunohistocytochemical validation of the presence of the biomarker using an antibody designed against the Cter part of RegAlpha. c The MALDI MS spectra of tissue extract from stage 1a serous OVC biopsies. The C-terminal Reg-alpha fragment $(m / z 9,744)$ is detected in the acini

alpha1-acid glycoprotein or AGP), which is normally increased in infection, inflammation and cancer, seems to have immunosuppressive properties in ovarian carcinoma ascites through inhibition of IL-2 secretion by lymphocytes [131]. Similarly, apolipoprotein A1 has been detected in conjunction with transthyretin and transferrin in earlystage mucinous tumors [132]. ApoA-I is known to decrease expression of surface molecules such as CD1a, CD80, CD86, and HLA-DR in dendritic cells and stimulates the production of IL-10 [133] (Fig. 2). Interestingly, hemopexin has recently been demonstrated to reduce TNF $\alpha$ and IL-6
B

Molecular Image of ion $\mathrm{m} / \mathrm{z} 9744$
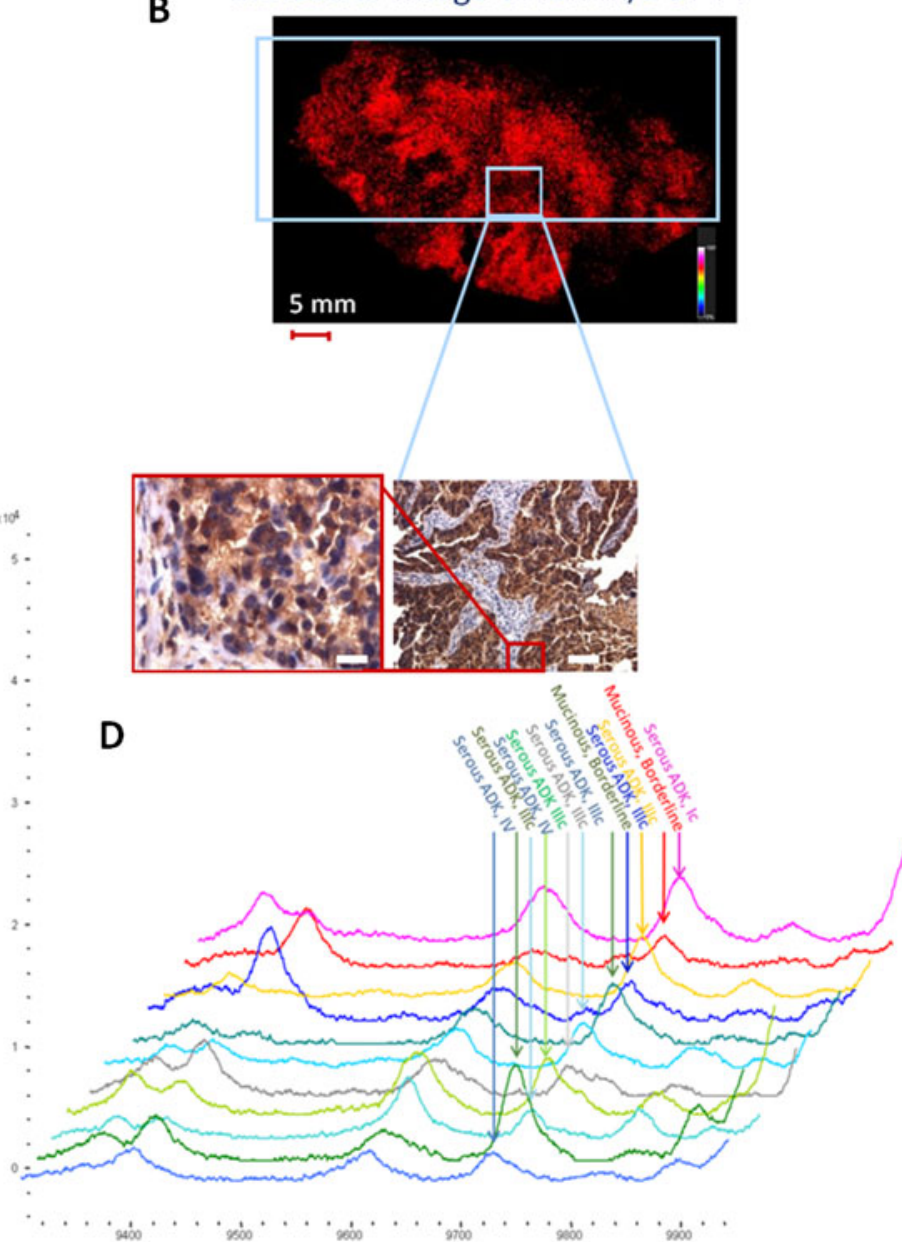

cells. The inset shows fluorescent immunocytochemistry data using the anti-C terminal Reg alpha fragment and hematoxylin and eosin (H\&E) staining of the tissue subjected to the MALDI MS profiling analyses (scale bar $5 \mathrm{~mm}$ ) [191]. d The MALDI MS spectra of the tissue extract from the carcinoma regions of ten patients at different pathologic stages after neoadjuvant chemotherapy. Mass spectra analyses of extracts from stages I, IIIc, and IV serous tumors after neoadjuvant chemotherapy. The ion with an $\mathrm{m} / \mathrm{z}$ ratio of 9774 corresponds to the C-terminal Reg-alpha fragment, is found in each patient and is indicated by an arrow. These data confirm that the C-terminal fragment of Reg alpha can be a good marker for the early diagnosis of tumor relapse (all tissues came from patients collected after neoadjuvant chemotherapy with 6 cycles of carboplatin/Taxol followed by carboplatin with Caelyx before complete surgery) [191]

from macrophages during inflammation and limits TLR4 and TLR2 agonist-induced macrophage cytokine production [134]. In SKOV-3 epithelial ovarian carcinoma cells, all TLRs are overexpressed with the exception of TLR9 and TLR10 [1]. This is in line with the overexpression of lumican, which is a small LRR proteoglycan in the extracellular matrix. Along with other proteoglycans, such as decorin, biglycan, and prolargin, lumican is known to be overexpressed in breast cancer and playing a role in tumor progression $[135,136]$. However, as demonstrated for biglycan, which interacts with TLR2/4 on macrophages [137,138], we 
speculate that lumican is also involved in the activation of the inflammasome through TLR2/4 interaction. The activation of all danger-sensing receptors in carcinoma cells can be explained through the regulation of inflammation by carcinoma cells to facilitate tumor progression. In a sense, this implies that ovarian cancer cells use molecular mimicry as "parasites" to escape the immune response, as they produce immunosuppressors to achieve tolerance [139].

\section{Specific mechanisms underlying ovarian cancer metastasis}

The clinical and biological behavior of epithelial ovarian cancers differs from any other type of cancers. While the dissemination of cancerous cells in other carcinomatous afflictions requires the implication of vascular mechanisms of intra- and extravasation for the migration from the primary site to distant organs, ovarian carcinoma metastasis is a more passive event. Indeed, cells coming from the ovarian tumor often migrate to peritoneal organs with the physiological movement of peritoneal fluid but rarely create metastasis outside the peritoneum. This passive clinical mechanism is supported by some molecular changes in the cell elements for its anchoring to the remote metastatic sites. The surrounding cellular and tissular environment also promotes hosting of the cells outside the ovarian tumor. The first biological mechanism for cell migration is the epithelialmesenchymal transition (EMT) which facilitates the attachment of neoplastic cells to new tissue sites [82] (Fig. 4). Due to the lack of an anatomical barrier, ovarian carcinoma can spread directly throughout the peritoneal cavity, mainly by intra-abdominal dissemination and by lymphatic dissemination, enabling in this way the attachment to peritoneum and omentum. This event is characterized by proteins' and genes' modifications like epithelial intermediate filaments, whose expression is typically reduced, and in the overexpression of vimentin and matrix metalloproteases (MMPs). It has characterized by alterations in the expression of cell-to-cell adherents junctions and cell-matrix adhesion molecules including integrins and E-N-cadherin E-cadherin [140,141] (Fig. 4). It has recently also be validated that this event is related to an elevation of the expression of the glycoprotein MUC 4 [142]. E-cadherins allow the junction between the filaments of actin inside the cell and its cellular environment. This deficiency allows the cells to initiate its detachment from the tumor site. MUC4 is also associated to an elevation of other cadherins [143] such as N-cadherins, but also other mesenchymal markers such as Vimentin [142], which are also expressed and confer the cells an invasive phenotype. EMT confers as well the ability of cells to evolve in unfavorable conditions such as hypoxia [144]. Once the cell detached from the tumor site, the peritoneal environment of ascites starts the promotion of ovarian carcinoma cells proliferation and implantation in peritoneal sites. Growth factors play a critical role in motility and invasiveness of these cells where VEGF is one of the principal factors [145] (Fig. 4). It acts through EGFR, which has been proven to be overexpressed in $70 \%$ of carcinomas [146]. This process activates the MAPK pathway, which in turn contributes to the lack of cell-cell junctions. VEGF also activates the PI3K pathways, which contributes to the localization of the matrix metalloproteinase 9 at the membrane surface for the cleavage of E cadherins $[147,148]$. Moreover, VEGF stimulates ascite accumulation by increasing diaphragmatic and tumor associated vasculature $[145,149]$. Then, cancer cells can migrate through the peritoneum as single cells or groups of multiple cells called spheroid composed of multiple cells group. These spheroids present at their surface $\alpha 5 \beta 1$ integrin, which play a role in these spheroid formation [150] and its ligand fibronectin, important for spheroid growth. Other couples integrin/ligand exist such as $\alpha 6 \beta 1$ integrin/laminin and $\alpha 2 \beta 1$-integrin/type IV collagen, which intervenes in the attachment of the spheroids with the mesothelium of the peritoneum and the omentum [151]. In the process of cellular invasion, proteolytic enzymes are mandatory in order to release the spheroids to the peritoneal environment. Matrix metalloproteinase type I and II play this role in the primary cancerization steps $[152,153]$. After the transit in the peritoneum, cancerous cells acceed and attach to the peritoneum, which is constituted by mesothelial cells with collagen types I and IV, fibronectin and laminin. Coupled integrins then act for the attachment. At this step, VCAM is also a membrane protein at the surface of mesothelial cells that binds $\alpha 4 \beta 1$ integrin from the cancerous cells surface [154]. With the integrins, CD44 can also be an element of binding, which attachs to hyaluronic acid [155]. Additionally, adhesion molecules such as NCAM can promote ovarian cancer metastasis via the interaction with receptors such as FGFR [156]. Proteolytic activity is a requested mechanism for cells attachment since MMP-2, at the surface of cancer cells, cleaves fibronectin and vitronectin (extracellular matrix proteins) into smaller fragments to increase adhesion, respectively, with $\alpha 5 \beta 1 \alpha v \beta 3$ integrins $[157,158]$. Furthermore, host cells produce MMP9 to improve adhesion of cancerous cells [159]. Transglutaminases are another family of enzymes for cellular adhesion, in which transglutaminase 2 plays a major role in the relaxation of extracellular matrix and the regulation of MMP2 [160]. Enzymes of the kallikrein family have also been found to play a role in extracellular matrix degradation [161] (Fig. 4).

The last phases of metastasis progression consist in the final hosting of the cells groups in the peritoneal tissues. This mainly consists in the recruitment of new blood vessels within the host tissue in order to provide a complete nutritional autonomy to the new tumor site. VEGFs are then needed to stimulate vascular lymphatic endothelium in order 


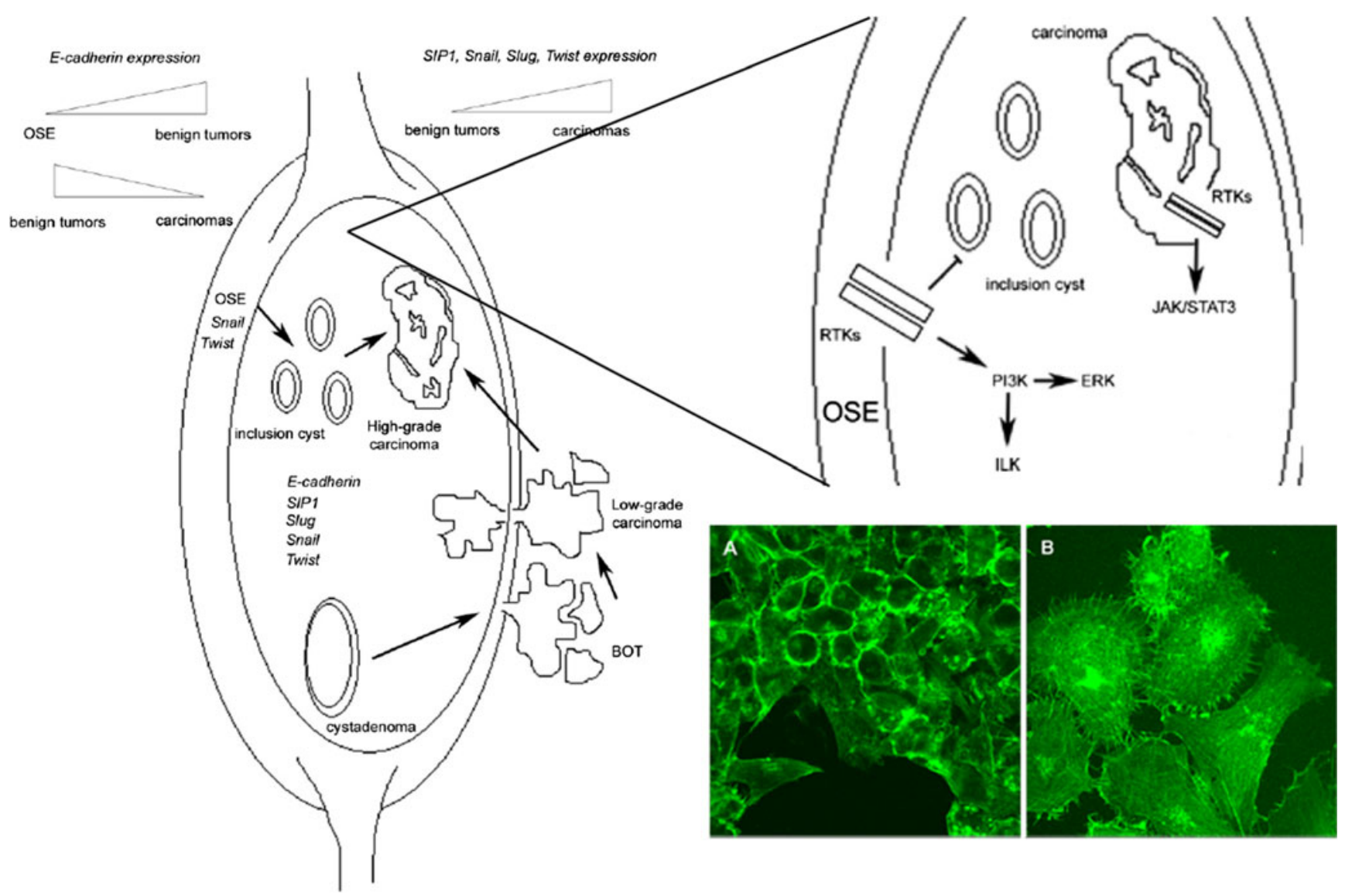

Fig. 4 Schematic illustration of E-cadherin, SIP1, Snail, Slug, and Twist during ovarian progression. A model has been proposed by Shih and Kurman in 2004 to explain ovarian cancer progression [83]. In this model, epithelial ovarian tumors have been classified into two broad categories: type I tumors including low-grade serous carcinomas, mucinous, endometrioid, and clear cells carcinomas seem to develop from their precursors, namely borderline ovarian tumors (BOTs), in a stepwise manner; type II including high-grade serous malignancies develop from the OSE or inclusion cysts without a common precursor.OSE cells covering the ovarian surface do not express E-cadherin but are positive for Snail and Twist expression. As depicted, E-cadherin expression changes during ovarian cancer progression showing an inverse correlation compared to SIP1, Snail, Slug and Twist expression. The zoom corresponds to A simplified overview of signalling network

to create new blood and lymphatic vessels. This process is the very last step of metastasis, that's why the expression of VEGF in ovarian carcinoma context is generally associated to poor prognosis [162]. Periostin has also been explored for its ability to require angiogenes, in addition to known effects on EMT process [163].

As mentioned above, the environmental context provided by the ascites is of great influence on properties of ovarian cancer cells. It has been established that chemokines such as CXCL12 induces migration, integrin expression, proliferation, and invasion [164]. CCL25-CCR9 interaction also contributes to ovarian cancer migration, metalloprotease expression, and invasion [165]. The hosting tissue is particularly important for metastasis efficiency since adipocytes regulating EGF-induced EMT. In OSE cells, activation of the EGF receptor tyrosine kinases (RTKs) by EGF results in activation of the phosphatidylinositol 3-kinase (PI3K), which activates ILK and ERK pathways. EGF treated OSE cells display a molecular signature characteristic of EMT and are less likely to undergo a conversion in inclusion cysts. JAK/STAT3 pathway is required to induce EMT in ovarian cancer cells. Ovarian cancer cells that undergo EMT lose the expression of E-cadherin and NGAL and show an increased motility [82]). Pictures illustrate human epithelial ovarian cancer cell line SKOV3 treated with (b) or without (a) TGF- $\beta\left(10 \mathrm{ng} \mathrm{ml}^{-1}\right)$. a Control cells have a typical epithelial-like morphology in culture flask/Petri with the tendency to form dense colonies. The filamentous actin cytoskeleton shows circumferential organization. b Protusive structures and actin stress fibers are clearly visible only in treated cells

of the omentum, which is a common site for ovarian tumor dissemination, can interact with the cells groups by adipokines such as IL8. IL8 can mediate homing, migration, and invasion of ovarian cancer cells. Besides, adipocytes can induce $\beta$-oxidation in cancer cells. Finally, the fatty-acidbinding protein 4 has been found to be overexpressed and plays a key role in ovarian cancer cells [166]. The cellular context in the peritoneum is also of high relevance. For example, cancer-associated fibroblasts (CAF) promote angiogenesis and lymphangiogenesis, tumor progression and metastasis by secreting different growth factors in the peritoneal environment [167].

Recent "omics" studies aimed to explore the complete molecular aspects of ovarian cancer metastasis. 
In 2010, Xu team established an in vivo model of ovarian cancer metastasis by injecting the well-known SKOV-3 cell line in nude mice peritoneum [168]. Then, serum proteins of the mice were analyzed by LC-MS/MS. Thirteen human proteins were identified, including three proteins that were highly relevant biomarkers for ovarian cancer metastasis. These candidates were tested for their relevance in blood screening of biomarkers by ELISA assays for patients with different stages of cancer progression. 14-3-3 zeta was found to have $90 \%, 82.5 \%, 72 \%$, and $94.3 \%$ sensitivity, specificity, positive predictive value (PPV), and negative predictive value (NPV), respectively, for stage I and stage II patients. 14-3-3 zeta is an adaptor protein that binds to other upstream or downstream signaling molecules containing tandem repeats of phosphoserine motifs $[169,170]$ and has been found to form a ternary complex with integrin alpha- 4 to accelerate cell migration [171]. This study highlights that metastasis of ovarian cancer is an early event since a protein involved in this behavior can be detected as a biomarker for early ovarian cancer. In another study, another member of the 14-3-3 familly, 14-3-3 sigma, has been found to protect the cancer against oxidative stress by inducing an insensitiveness of the cells to high $\mathrm{O}_{2}$ concentrations [172].

In 2011, Kakar team aimed for insights into the "metabolome" of ovarian cancer using GC/MS-TOF [173]. By this approach, they have been able to deduce the metabolic pathways involved in ovarian cancer metastasis behavior. This study revealed that ovarian cancer metastasis have altered carbohydrate metabolism. The ovarian cancer metastatic cells prefer to use glucose for anaerobic glycolysis instead of oxidative phosphorylation for the generation of ATP. This was revealed by an increased level of lactate. Fucose was also increased, coinciding with the elevated glycoproteins in ovarian cancer cells. Also, stimulation of proliferation has been related to the overconcentration of phenylactates. Antioxidants have also been found such as tocopherols and glutathione, concording with previous studies of protective behavior of ovarian metastatic cells against oxidative stress.

Recently, using MALDI mass spectrometry imaging coupled to on tissue microproteomics, we discovered in ovarian carcinoma proteins involved in metabolic processes particularly over-expressed like the pyruvate kinase isoenzyme M1/M2 (PKM2), the Vitamin D binding protein isoform 2 (DBP), the vitamin $\mathrm{K}$ epoxide reductase complex subunit 1 (VKORC1), the fatty acid-binding protein (FABP), the coactivator of PPAR-gamma-like proteins (Longuespéee unpublished data). These results reinforced the close correlation between proteome and metabolome expression during ovarian cancer metastasis.

Clearly, the results prove that novel tools, combined with appropriate models could be used to understand the specific mechanisms required for ovarian cancer metastasis.

\section{Relevant biomarkers for clinical diagnosis of ovarian cancer}

Amongst the molecules discovered and integrated in the understanding of OVC process mechanisms, some have been evaluated for their clinical relevance. In this part of the review, we have summarized the most promising markers that could be used for OVC screening in women populations. To date, CA 125 is the most widely used marker for the disease screening. In normal physiological conditions, ovary surface epithelium does not express CA 125 [174]. The level of seric CA 125 is considered as normal when it is not higher than $35 \mathrm{U} / \mathrm{mL}$ [175]. Levels higher than $35 \mathrm{U} / \mathrm{mL}$ are found in $90 \%$ of patients with advanced stage disease and in $50 \%$ of stage I cancer patients [176]. CA 125 is exclusively used to monitor the effect of chemotherapies or targeted therapies on the disease. Thus, it is useless for the screening of large scale supervision of the healthiness of postmenopausal women.

The detection of molecular factors for ovarian cancer process was then undertaken in large cohorts of patients and found to provide relatively good results for ovarian cancer screening. Interleukin 13 (IL13) is a cytokine with an inflammatory activity that plays important roles in many biological activities. The level of this cytokine has been measured and found more elevated in cancerous tissues [177]. IL13 receptor is composed by two strands (ILA3Ra1 and IL13Ra2) and the second one has been found in high levels in 44 of 53 of ovarian cancer samples [178]. A cytotoxic therapy mediated by IL- 13 have been designed and tested in phase I/II clinical trial. This therapy showed an antitumor activity and was very efficient when administered intraperitoneally, since it blocks the spread of ovarian cancer cells through the peritoneum in late stages of ovarian cancer [178]. The serum macrophage inhibitory factor MIF have also been tested for its presence in the blood of ovarian cancer patients and a sensitivity of $77.8 \%$ and a specificity of $53.3 \%$ were measured for this marker [116]. HE4 has also been identified as a potential discriminator of ovarian cancers [179]. This marker, tested in blinded studies on post menopausal patients, was found to have similar discriminating characteristics to CA 125 . Many markers were found to be much more efficient for ovarian cancer discrimination, when used in conjunction of CA 125. Macrophage-colony stimulating factor (M-CSF) [180] has been used alone and detected ovarian cancer with a specificity of around 61$68 \%$ and $93 \%$ specificity [181], but the results for the detection were better when used in conjunction with CA 125 [182]. Indeed, the use of either CA 125 or M-CSF enabled the identification of $96-98 \%$ of ovarian cancers and $81 \%$ of early stages [180]. Another marker, the lysophosphatidic acid, has been reported to have a sensitivity of $100 \%$ for high stages cancers and $90 \%$ for stage I cancers[183]. Some 
panels of biomarkers have also been proposed for high sensitivity/specificity tests of ovarian cancer screening. The use of the combination of 5 markers (CA 125, OVX1, LASA, CA 15-3, CA 72-4) showed sensitivity of $90.6 \%$ and specificity of $93.2 \%$, when included in CART analysis (classification and regression tree analysis), which is a marker-based classification algorithm of the disease [184]. Four other markers (CA 125, CA72-4, CA 15-3, and PLA) were found to have a sensitivity from $68 \%$ to $87 \%$ and the same specificity as for CA 125 [185]. Thus, the use of panels of biomarkers seems to be mandatory for biomarker screening. This is particularly well illustrated by the study of Leiser and coll. who proposed the use of six markers (leptin, prolactin, osteopontin, IGFII, MIF, and CA 125) to discriminate ovarian cancer and benign tissues with an accuracy of $89 \%$ for early stages cancers and $100 \%$ for late stage disease. However, none of these markers used alone was able to discriminate properly diseased and unaffected samples [186]. Recently, association of some of the markers presented here, namely mesothelin, osteopontin, and HE4 have been selected by the Specialized Program of Research Excellence (SPORE) committee for their good sensitivity and specificity values [187].

\section{Conclusion}

This review attempts to link OVC genes polymorphisms to cell signaling pathways which play a central role in cancer cell growth, survival, invasion metastasis, and immune escape.
The integration of these OVC data, as a function of the grade and tumor type, with specific sets of markers is important in order to link the pathology with improved diagnosis and even for therapeutic benefits. The clinical relevance of these OVC molecular factors then need to be validated by large scale screening studies of patient samples, with an emphasis on attempting to screen in the early stages of the diseases. The development of proteomic approaches in the field of biomarkers research has greatly enhanced the discovery of relevant molecular markers for multiple diseases. In the case of OVC, these new markers could provide an alternative strategy to the actual CA 125 monitoring test.

In this review, we conclude that MALDI-MSI is one of the most promising proteomic methods for biomarker discovery, as it allows the direct analysis of tissue sections and large scale screening of markers in their anatomical context. The growing interest for MALDI-MSI in the proteomics community is due to the increasing ease of use, great accuracy, and statistical power, as it is now combined with adapted statistical tools. MALDI-MSI may soon become the primary approach for the biomarkers discovery. In this review, we also conclude as to the difficulty in correlating between predicting important genes in pathologies and biomarker detection in tissue and in serum. Nevertheless, the association multiplex panel of biomarkers has also been proposed to increase the sensitivity/specificity testing of ovarian cancer screening associated with CA125. Novel biomarkers identified by MALDI-MSI, i.e., the C-terminal fragment of Reg-alpha and Mucin 9 as well as specific viral signatures
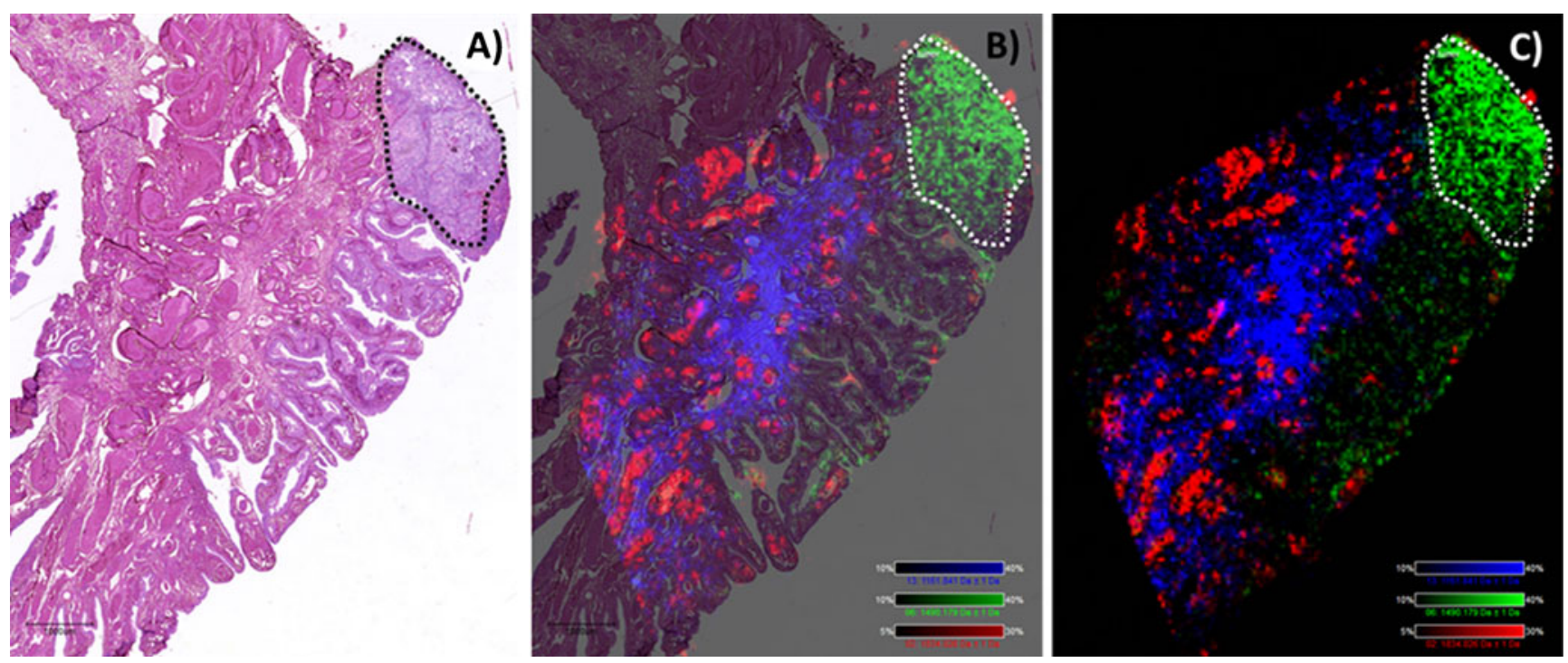

Fig. 5 Molecular localization of three different ions on a FFPE tissue section in the region Fimbria of the uterine tube. Histological section after hematoxylin eosin-safran (HES) coloration (a). Ions images at a spatial resolution of $50 \mu \mathrm{m}$ with (b) or without (c) a superposition of the histological image. Three specific molecules were localized in the blood vessel (in red), in the mesothelium (in blue) and specific to the cancer region (in green) 
(EBV, HHV6) may allow the assembly of more complete biomarker panels for early ovarian cancer diagnosis. In order to increase specificity, it will be necessary to take into account not only protein biomarkers linked to cell modifications but also the presence of specific viral proteins, the etiology of the pathology (e.g., the Mullerian cell origin of ovarian serous cancer) and their specific markers. Most ovarian carcinomas associated with deleterious mutations BRCA1/2 appear to derive from the tube, especially its fimbria. These cancers are almost always high-grade serous ovarian, tubal, or peritoneal. Given the ineffectiveness of current screening, bilateral salpingo-oophorectomy is the preferred prophylactic procedure. This procedure is not without consequences and in view of pathogenesis data reviewed, it may be possible to perform a temporary prophylaxis in the form of a bilateral radical fimbriectomie. Recent histopathological studies support the possibility of tumors forming at epithelialmesothelial junctions (peritoneal mesothelioma between epithelium and Mullerian or between tubal epithelium and tubal and ovarian mesothelium lining). This hypothesis is in line with tumors cervix or the cardia which are also "pathologies junction" between coatings of different natures. The hypothesis of an abnormal spread of cells on the cortical tubal or ovarian inclusion cysts, and their development into carcinoma, is corroborated by very recent biomolecular studies. They confirm the expression by cancer cells of high-grade serous mullerian markers (like the duct) but not mesothelium (such as ovarian cortex) [188-190]. Hypothesis that can be drawn is the fact that high-grade serous carcinoma would be a secondary malignance of the ovary and not a primary ovarian tumor Type 1 lesions will find their origin in the carcinogenesis of inclusion cysts post-ovulation, which, during the healing of the breach ovarian tissue would then reflect a Mullerian origin [188-190]. The type of carcinoma depends on the origin of these Mullerian cells. It is therefore necessary to integrate these notions in ovarian cancer diagnosis and identify specific markers in relation with these Mullerian cells. MALDI-MSI (Fig. 5) can offer versatile and powerful methods to investigate these junctions, on specimens of prophylactic oophorectomy or in fimbriectomies with mutated BRCA $1 / 2$, in order to detect early abnormalities and help explain tumor development while identifying early disease biomarkers.

Acknowledgements Supported by grants from Agence Nationale de la Recherche (ANR PCV to IF), Institut du Cancer (INCA to IF), Institut de Recherche en Santé du Canada (ISRC to MS \& RD), the Ministère du Développement Économique de l'Innovation et de l'Exportation (MDEIE to R.D), the Fond de la recherche du Québec Santé (FRQS to R.D), the Université de Sherbrooke and the Région Nord-Pas de Calais (to RL). R.D. is a member of the Centre de Recherche Clinique Etienne-Le Bel (Sherbrooke, Qc, Canada).

\section{References}

1. Longuespée RB, C., Kerdraon, O., Vinatier, D., Fournier, I., Day, R., Salzet, M. (2012). MALDI MSI and Ovarian cancer Biomarkers. Advances in Cancer Management; Ed R. Mohan, Chap. 10, 211-236.

2. Jelovac, D., Armstrong, D.K. Recent progress in the diagnosis and treatment of ovarian cancer. CA: A Cancer Journal for Clinicians, 61, 183-203.

3. Konishi, H., Mohseni, M., Tamaki, A, et al. 2011. Mutation of a single allele of the cancer susceptibility gene BRCA1 leads to genomic instability in human breast epithelial cells. Proceedings of the National Academy of Sciences of the United States of America, 108, 17773-17778.

4. Saunders, K.H., Nazareth, S., Pressman, P.I. (2011). Case report: BRCA in the Ashkenazi population: are current testing guidelines too exclusive? Heredity Cancer Clinical Practice, 9(1), 3.

5. Jazaeri, A. A. (2009). Molecular profiles of hereditary epithelial ovarian cancers and their implications for the biology of this disease. Molecular Oncology, 3, 151-156.

6. Bast, R. C., Jr., Hennessy, B., \& Mills, G. B. (2009). The biology of ovarian cancer: new opportunities for translation. Nature Reviews. Cancer, 9, 415-428.

7. Moore, L.E., Pfeiffer, R.M., Zhang, Z., Lu, K.H., Fung, E.T., Bast, R.C., Jr. (2012). Proteomic biomarkers in combination with CA 125 for detection of epithelial ovarian cancer using prediagnostic serum samples from the prostate, lung, colorectal, and ovarian (PLCO) cancer screening trial. Cancer, 118(1), 91-100.

8. Vaughan, S., Coward, J. I., Bast, R. C., Jr., et al. (2011). Rethinking ovarian cancer: recommendations for improving outcomes. Nature Reviews. Cancer, 11, 719-725.

9. Moore, R. G., MacLaughlan, S., \& Bast, R. C., Jr. (2010). Current state of biomarker development for clinical application in epithelial ovarian cancer. Gynecologic Oncology, 116, 240-245.

10. Lu, Z., \& Bast, R. C., Jr. (2009). Tumor suppressor genes. Cancer Treatment and Research, 149, 109-129.

11. Samanta, A. K., Huang, H. J., Le, X. F., et al. (2009). MEKK3 expression correlates with nuclear factor kappa B activity and with expression of antiapoptotic genes in serous ovarian carcinoma. Cancer, 115, 3897-3908.

12. Huang, S., Chang, I.S., Lin, W., et al. 2009. ARHI (DIRAS3), an imprinted tumour suppressor gene, binds to importins and blocks nuclear import of cargo proteins. Bioscience Reports, 30, 159-168.

13. Kan, Z., Jaiswal, B. S., Stinson, J., et al. (2011). Diverse somatic mutation patterns and pathway alterations in human cancers. Nature, 466, 869-873.

14. Bast, R. C., Jr., \& Spriggs, D. R. (2011). More than a biomarker: CA125 may contribute to ovarian cancer pathogenesis. Gynecologic Oncology, 121, 429-430.

15. Zhu, C. S., Pinsky, P. F., Cramer, D. W., et al. (2011). A framework for evaluating biomarkers for early detection: validation of biomarker panels for ovarian cancer. Cancer Prevention Research (Philadelphia, Pa.), 4, 375-383.

16. Kalachand, R., Hennessy, B. T., \& Markman, M. (2011). Molecular targeted therapy in ovarian cancer: what is on the horizon? Drugs, 71, 947-967.

17. Wilson, E. B., El-Jawhari, J. J., Neilson, A. L., et al. (2001). Human tumour immune evasion via TGF-beta blocks NK cell activation but not survival allowing therapeutic restoration of anti-tumour activity. PLoS One, 6, e22842.

18. Papacleovoulou, G., Critchley, H., Hillier, S.G., Mason, J.I. (2011). IL-1 \{alpha\} and IL-4 signalling in human ovarian surface epithelial cells. Journal of Endocrinology, 211(3), 273-283.

19. Barbolina, M. V., Burkhalter, R. J., \& Stack, M. S. (2011). Diverse mechanisms for activation of Wnt signalling in the 
ovarian tumour microenvironment. Biochemistry Journal, 437, $1-12$.

20. Comamala, M., Pinard, M., Theriault, C., et al. (2011). Downregulation of cell surface CA125/MUC16 induces epithelial-tomesenchymal transition and restores EGFR signalling in NIH: OVCAR3 ovarian carcinoma cells. British Journal of Cancer, 104, 989-999.

21. Mazzoletti, M., \& Broggini, M. (2010). PI3K/AKT/mTOR inhibitors in ovarian cancer. Current Medicinal Chemistry, 17, 44334447.

22. Hipp, S., Berg, D., Ergin, B., et al. (2010). Interaction of Snail and p38 mitogen-activated protein kinase results in shorter overall survival of ovarian cancer patients. Virchows Archiv, 457, 705-713.

23. Bolitho, C., Hahn, M. A., Baxter, R. C., \& Marsh, D. J. (2010). The chemokine CXCL1 induces proliferation in epithelial ovarian cancer cells by transactivation of the epidermal growth factor receptor. Endocrine-Related Cancer, 17, 929-940.

24. Mertens-Walker, I., Bolitho, C., Baxter, R. C., \& Marsh, D. J. (2010). Gonadotropin-induced ovarian cancer cell migration and proliferation require extracellular signal-regulated kinase $1 / 2$ activation regulated by calcium and protein kinase $\mathrm{C}\{$ delta $\}$. Endocrine-Related Cancer, 17, 335-349.

25. Falasca, M., Chiozzotto, D., Godage, H. Y., et al. (2010). A novel inhibitor of the PI3K/Akt pathway based on the structure of inositol 1,3,4,5,6-pentakisphosphate. British Journal of Cancer, 102, 104-114.

26. Drummond, A. E., \& Fuller, P. J. (2010). The importance of ERbeta signalling in the ovary. Journal of Endocrinology, 205, 15-23.

27. Herrera, B., van Dinther, M., Ten Dijke, P., \& Inman, G. J. (2009). Autocrine bone morphogenetic protein-9 signals through activin receptor-like kinase-2/Smad1/Smad4 to promote ovarian cancer cell proliferation. Cancer Research, 69, 9254-9262.

28. Helleman, J., Jansen, M. P., Burger, C., van der Burg, M. E., \& Berns, E. M. (2010). Integrated genomics of chemotherapy resistant ovarian cancer: a role for extracellular matrix, TGFbeta and regulating microRNAs. The International Journal of Biochemistry \& Cell Biology, 42, 25-30.

29. Papachroni, K.K., Piperi, C., Levidou, G., et al. Lysyl oxidase interacts with AGE signalling to modulate collagen synthesis in polycystic ovarian tissue. 2010. Journal of Cellular and Molecular Medicine, 14, 2460-2469.

30. Wang, Y., Nicholls, P. K., Stanton, P. G., et al. (2009). Extraovarian expression and activity of growth differentiation factor 9. Journal of Endocrinology, 202, 419-430.

31. Drake, J., Shearwood, A. M., White, J., et al. (2009). Expression of secreted frizzled-related protein 4 (SFRP4) in primary serous ovarian tumours. European Journal of Gynaecological Oncology, 30, 133-141.

32. Santra, M. K., Wajapeyee, N., \& Green, M. R. (2009). F-box protein FBXO31 mediates cyclin D1 degradation to induce G1 arrest after DNA damage. Nature, 459, 722-725.

33. Trinh, X. B., Tjalma, W. A., Vermeulen, P. B., et al. (2009). The VEGF pathway and the AKT/mTOR/p70S6K1 signalling pathway in human epithelial ovarian cancer. British Journal of Cancer, 100, 971-978

34. Colomiere, M., Ward, A. C., Riley, C., et al. (2009). Cross talk of signals between EGFR and IL-6R through JAK2/STAT3 mediate epithelial-mesenchymal transition in ovarian carcinomas. British Journal of Cancer, 100, 134-144.

35. Kolasa, I. K., Rembiszewska, A., Felisiak, A., et al. (2009). PIK3CA amplification associates with resistance to chemotherapy in ovarian cancer patients. Cancer Biology \& Therapy, 8, 21-26.

36. Noske, A., Lindenberg, J. L., Darb-Esfahani, S., et al. (2008). Activation of mTOR in a subgroup of ovarian carcinomas: correlation with p-eIF-4E and prognosis. Oncology Reports, 20 , 1409-1417.

37. Colomiere, M., Findlay, J., Ackland, L., \& Ahmed, N. (2009). Epidermal growth factor-induced ovarian carcinoma cell migration is associated with JAK2/STAT3 signals and changes in the abundance and localization of alpha6beta1 integrin. The International Journal of Biochemistry \& Cell Biology, 41, 1034-1045.

38. Papacleovoulou, G., Edmondson, R. J., Critchley, H. O., Hillier, S. G., \& Mason, J. I. (2009). 3beta-Hydroxysteroid dehydrogenases and pre-receptor steroid metabolism in the human ovarian surface epithelium. Molecular and Cellular Endocrinology, $301,65-73$.

39. de Graeff, P., Crijns, A. P., Ten Hoor, K. A., et al. (2008). The ErbB signalling pathway: protein expression and prognostic value in epithelial ovarian cancer. British Journal of Cancer, 99, 341-349.

40. Bleeker, F. E., Felicioni, L., Buttitta, F., et al. (2008). AKT1 (E17K) in human solid tumours. Oncogene, 27, 5648-5650.

41. Guo, R. X., Qiao, Y. H., Zhou, Y., Li, L. X., Shi, H. R., \& Chen, K. S. (2008). Increased staining for phosphorylated AKT and nuclear factor-kappaB p65 and their relationship with prognosis in epithelial ovarian cancer. Pathology International, 58, 749756.

42. Guo, L. M., Pu, Y., Han, Z., et al. (2009). MicroRNA-9 inhibits ovarian cancer cell growth through regulation of NF-kappaB1. FEBS Journal, 276, 5537-5546.

43. Karin, M. (2006). Nuclear factor-kappaB in cancer development and progression. Nature, 441, 431-436.

44. Karin, M. (2006). NF-kappaB and cancer: mechanisms and targets. Molecular Carcinogenesis, 45, 355-361.

45. Karin, M., Lawrence, T., \& Nizet, V. (2006). Innate immunity gone awry: linking microbial infections to chronic inflammation and cancer. Cell, 124, 823-835.

46. Manzano, R. G., Montuenga, L. M., Dayton, M., et al. (2002). CL100 expression is down-regulated in advanced epithelial ovarian cancer and its re-expression decreases its malignant potential. Oncogene, 21, 4435-4447.

47. Lengyel, E., Stepp, E., Gum, R., \& Boyd, D. (1995). Involvement of a mitogen-activated protein kinase signaling pathway in the regulation of urokinase promoter activity by c-Ha-ras. Journal of Biological Chemistry, 270, 23007-23012.

48. Felip, E., Encabo, G., Vidal, M. T., Vera, R., del Campo, J. M., \& Rubio, D. (1995). C-erbB-2 protein in ovarian epithelial cancer: correlation between expression in tumor tissue and blood levels. Medicina Clínica (Barcelona), 105, 5-8.

49. Felip, E., Del Campo, J. M., Rubio, D., Vidal, M. T., Colomer, R., \& Bermejo, B. (1995). Overexpression of c-erbB-2 in epithelial ovarian cancer. Prognostic value and relationship with response to chemotherapy. Cancer, 75, 2147-2152.

50. Teixeira, J., Maheswaran, S., \& Donahoe, P. K. (2001). Mullerian inhibiting substance: an instructive developmental hormone with diagnostic and possible therapeutic applications. Endocrine Reviews, 22, 657-674.

51. Braun, A. H., \& Coffey, R. J. (2005). Lysophosphatidic acid, a disintegrin and metalloprotease-17 and heparin-binding epidermal growth factor-like growth factor in ovarian cancer: the first word, not the last. Clinical Cancer Research, 11, 4639-4643.

52. Gewinner, C., Wang, Z. C., Richardson, A., et al. (2009). Evidence that inositol polyphosphate 4-phosphatase type II is a tumor suppressor that inhibits PI3K signaling. Cancer Cell, 16, 115-125.

53. Imamov, O., Shim, G. J., Warner, M., \& Gustafsson, J. A. (2005). Estrogen receptor beta in health and disease. Biology of Reproduction, 73, 866-871.

54. Lindgren, P. R., Cajander, S., Backstrom, T., Gustafsson, J. A., Makela, S., \& Olofsson, J. I. (2004). Estrogen and progesterone 
receptors in ovarian epithelial tumors. Molecular and Cellular Endocrinology, 221, 97-104.

55. Li, A. J., Baldwin, R. L., \& Karlan, B. Y. (2003). Estrogen and progesterone receptor subtype expression in normal and malignant ovarian epithelial cell cultures. American Journal of Obstetrics and Gynecology, 189, 22-27.

56. Lazennec, G. (2005). Retraction: article on estrogen receptor beta in ovarian carcinogenesis. Cancer Research, 65, 5480.

57. Ye, B., Cramer, D. W., Skates, S. J., et al. (2003). Haptoglobinalpha subunit as potential serum biomarker in ovarian cancer: identification and characterization using proteomic profiling and mass spectrometry. Clinical Cancer Research, 9, 2904-2911.

58. Yu, J. K., Zheng, S., Tang, Y., \& Li, L. (2005). An integrated approach utilizing proteomics and bioinformatics to detect ovarian cancer. Journal of Zhejiang University. Science. B, 6, 227-231.

59. Conrads, T. P., Fusaro, V. A., Ross, S., et al. (2004). Highresolution serum proteomic features for ovarian cancer detection. Endocrine-Related Cancer, 11, 163-178.

60. Zhu, Y., Wu, R., Sangha, N., et al. (2006). Classifications of ovarian cancer tissues by proteomic patterns. Proteomics, 6, 5846-5856.

61. Kim, H., Wu, R., Cho, K. R., et al. (2008). Comparative proteomic analysis of low stage and high stage endometrioid ovarian adenocarcinomas. Proteomics. Clinical Applications, 2, 571-584.

62. Lemaire, R., Menguellet, S. A., Stauber, J., et al. (2007). Specific MALDI imaging and profiling for biomarker hunting and validation: fragment of the $11 \mathrm{~S}$ proteasome activator complex, Reg alpha fragment, is a new potential ovary cancer biomarker. Journal of Proteome Research, 6, 4127-4134.

63. Franck, J., Arafah, K., Elayed, M., et al. (2009). MALDI imaging mass spectrometry: state of the art technology in clinical proteomics. Molecular \& Cellular Proteomics, 8, 2023-2033.

64. Gustafsson, J. O., Oehler, M. K., McColl, S. R., \& Hoffmann, P. (2010). Citric acid antigen retrieval (CAAR) for tryptic peptide imaging directly on archived formalin-fixed paraffin-embedded tissue. Journal of Proteome Research, 9, 4315-4328.

65. Gustafsson, J. O., Oehler, M. K., Ruszkiewicz, A., McColl, S. R., \& Hoffmann, P. (2011). MALDI Imaging Mass Spectrometry (MALDI-IMS)-Application of Spatial Proteomics for Ovarian Cancer Classification and Diagnosis. International Journal of Molecular Sciences, 12, 773-794.

66. Kikuchi, N., Horiuchi, A., Osada, R., et al. (2006). Nuclear expression of S100A4 is associated with aggressive behavior of epithelial ovarian carcinoma: an important autocrine/paracrine factor in tumor progression. Cancer Science, 97, 1061-1069.

67. El Ayed, M., Bonnel, D., Longuespee, R., et al. (2010). MALDI imaging mass spectrometry in ovarian cancer for tracking, identifying, and validating biomarkers. Medical Science Monitor, 16, BR233-BR245.

68. Gortzak-Uzan, L., Ignatchenko, A., Evangelou, A. I., et al. (2008). A proteome resource of ovarian cancer ascites: integrated proteomic and bioinformatic analyses to identify putative biomarkers. Journal of Proteome Research, 7, 339-351.

69. Makino, E., Sakaguchi, M., Iwatsuki, K., \& Huh, N. H. (2004). Introduction of an N-terminal peptide of S100C/A11 into human cells induces apoptotic cell death. Journal of Molecular Medicine, 82, 612-620.

70. Sakaguchi, M., Miyazaki, M., Sonegawa, H., et al. (2004). PKCalpha mediates TGFbeta-induced growth inhibition of human keratinocytes via phosphorylation of S100C/A11. The Journal of Cell Biology, 164, 979-984.

71. Yang, Z., Tao, T., Raftery, M. J., Youssef, P., Di Girolamo, N., \& Geczy, C. L. (2001). Proinflammatory properties of the human S100 protein S100A12. Journal of Leukocyte Biology, 69, 986-994.

72. Do, T. V., Kubba, L. A., Du, H., Sturgis, C. D., \& Woodruff, T. K. (2008). Transforming growth factor-beta1, transforming growth factor-beta2, and transforming growth factor-beta3 enhance ovarian cancer metastatic potential by inducing a Smad3-dependent epithelial-to-mesenchymal transition. Molecular Cancer Research, 6, 695-705.

73. Rodriguez, G. C., Haisley, C., Hurteau, J., et al. (2001). Regulation of invasion of epithelial ovarian cancer by transforming growth factor-beta. Gynecologic Oncology, 80, 245-253.

74. Sood, A. K., Fletcher, M. S., Coffin, J. E., et al. (2004). Functional role of matrix metalloproteinases in ovarian tumor cell plasticity. American Journal of Obstetrics and Gynecology, 190, 899-909.

75. Sood, A. K., Seftor, E. A., Fletcher, M. S., et al. (2001). Molecular determinants of ovarian cancer plasticity. American Journal of Pathology, 158, 1279-1288.

76. Vergara, D., Merlot, B., Lucot, J.P., et al. (2010). Epithelialmesenchymal transition in ovarian cancer. Cancer Letters, 291 (1), 59-66.

77. Giuntoli, R. L., 2nd, Webb, T. J., Zoso, A., et al. (2009). Ovarian cancer-associated ascites demonstrates altered immune environment: implications for antitumor immunity. Anticancer Research, 29, 2875-2884.

78. Xie, X., Ye, D., Chen, H., Lu, W., Cheng, B., \& Zhong, H. (2004). Interleukin-7 and suppression of local peritoneal immunity in ovarian carcinoma. International Journal of Gynaecology and Obstetrics, 85, 151-158.

79. Lambeck, A. J., Crijns, A. P., Leffers, N., et al. (2007). Serum cytokine profiling as a diagnostic and prognostic tool in ovarian cancer: a potential role for interleukin 7. Clinical Cancer Research, 13, 2385-2391.

80. Kitagawa, K., Murata, A., Matsuura, N., et al. (1996). Epithelialmesenchymal transformation of a newly established cell line from ovarian adenosarcoma by transforming growth factor-beta1. International Journal of Cancer, 66, 91-97.

81. Keshamouni, V. G., Michailidis, G., Grasso, C. S., et al. (2006). Differential protein expression profiling by iTRAQ-2DLC-MS/ MS of lung cancer cells undergoing epithelial-mesenchymal transition reveals a migratory/invasive phenotype. Journal of Proteome Research, 5, 1143-1154.

82. Vergara, D., Merlot, B., Lucot, J. P., et al. (2010). Epithelial-mesenchymal transition in ovarian cancer. Cancer Letters, 291, 59-66.

83. Mor, G., Visintin, I., Lai, Y., et al. (2005). Serum protein markers for early detection of ovarian cancer. Proceedings of the National Academy of Sciences of the United States of America, 102, 7677-7682.

84. Choi, J. H., Lee, K. T., \& Leung, P. C. (2011). Estrogen receptor alpha pathway is involved in leptin-induced ovarian cancer cell growth. Carcinogenesis, 32, 589-596.

85. Levina, V. V., Nolen, B., Su, Y., et al. (2009). Biological significance of prolactin in gynecologic cancers. Cancer Research, 69 , $5226-5233$.

86. Song, G., Cai, Q. F., Mao, Y. B., Ming, Y. L., Bao, S. D., \& Ouyang, G. L. (2008). Osteopontin promotes ovarian cancer progression and cell survival and increases HIF-1alpha expression through the PI3-K/Akt pathway. Cancer Science, 99, 19011907.

87. Lee, E. J., Mircean, C., Shmulevich, I., et al. (2005). Insulin-like growth factor binding protein 2 promotes ovarian cancer cell invasion. Molecular Cancer, 4, 7.

88. Guo, X., Liu, G., Schauer, I. G., et al. (2011). Overexpression of the beta subunit of human chorionic gonadotropin promotes the transformation of human ovarian epithelial cells and ovarian tumorigenesis. American Journal of Pathology, 179, 1385-1393.

89. Boss, D.S., Glen, H., Beijnen, J.H., et al. Serum beta-HCG and CA-125 as tumor markers in a patient with osteosarcoma: case report. Tumori, 97, 109-114.

90. Pejcic, I., Vrbic, S., Filipovic, S., et al. (2010). [Significance of serum tumor markers monitoring metastases in carcinomas of unknown primary site]. Vojnosanitetski Pregled, 67, 723-731. 
91. Tavares Murta, B. M., Cunha Fde, Q., Miranda, R., Adad, S. J., \& Murta, E. F. (2004). Differential tumor microenvironment in human ovarian cystic tumors. Tumori, 90, 491-497.

92. Perkins, G. L., Slater, E. D., Sanders, G. K., \& Prichard, J. G. (2003). Serum tumor markers. American Family Physician, 68, 1075-1082.

93. Clarke, B., Tinker, A. V., Lee, C. H., et al. (2009). Intraepithelial $\mathrm{T}$ cells and prognosis in ovarian carcinoma: novel associations with stage, tumor type, and BRCA1 loss. Modern Pathology, 22, 393-402.

94. Curiel, T. J., Coukos, G., Zou, L., et al. (2004). Specific recruitment of regulatory $\mathrm{T}$ cells in ovarian carcinoma fosters immune privilege and predicts reduced survival. Nature Medicine, 10, 942-949.

95. Preston, C. C., Goode, E. L., Hartmann, L. C., Kalli, K. R., \& Knutson, K. L. (2011). Immunity and immune suppression in human ovarian cancer. Immunotherapy, 3, 539-556.

96. Yigit, R., Massuger, L. F., Figdor, C. G., \& Torensma, R. (2010). Ovarian cancer creates a suppressive microenvironment to escape immune elimination. Gynecologic Oncology, 117, 366-372.

97. Nonaka, H., Saga, Y., Fujiwara, H., et al. (2011). Indoleamine 2,3-dioxygenase promotes peritoneal dissemination of ovarian cancer through inhibition of natural killercell function and angiogenesis promotion. International Journal of Oncology, 38, 113120.

98. Ino, K. (2011). Indoleamine 2,3-dioxygenase and immune tolerance in ovarian cancer. Current Opinion in Obstetrics and Gynecology, 23, 13-18.

99. Inaba, T., Ino, K., Kajiyama, H., et al. (2009). Role of the immunosuppressive enzyme indoleamine 2,3-dioxygenase in the progression of ovarian carcinoma. Gynecologic Oncology, $115,185-192$.

100. Okamoto, A., Nikaido, T., Ochiai, K., et al. (2005). Indoleamine 2,3-dioxygenase serves as a marker of poor prognosis in gene expression profiles of serous ovarian cancer cells. Clinical Cancer Research, 11, 6030-6039.

101. Nelson, B. H. (2009). IDO and outcomes in ovarian cancer. Gynecologic Oncology, 115, 179-180.

102. Loercher, A. E., Nash, M. A., Kavanagh, J. J., Platsoucas, C. D., \& Freedman, R. S. (1999). Identification of an IL-10-producing HLA-DR-negative monocyte subset in the malignant ascites of patients with ovarian carcinoma that inhibits cytokine protein expression and proliferation of autologous $\mathrm{T}$ cells. The Journal of Immunology, 163, 6251-6260

103. Wei, S., Kryczek, I., Zou, L., et al. (2005). Plasmacytoid dendritic cells induce $\mathrm{CD} 8+$ regulatory $\mathrm{T}$ cells in human ovarian carcinoma. Cancer Research, 65, 5020-5026.

104. Jung, Y. W., Kim, Y. T., Kim, S. W., et al. (2009). Correlation of human leukocyte antigen-G (HLA-G) expression and disease progression in epithelial ovarian cancer. Reproductive Sciences, 16, 1103-1111.

105. Menier, C., Prevot, S., Carosella, E. D., \& Rouas-Freiss, N. (2009). Human leukocyte antigen-G is expressed in advancedstage ovarian carcinoma of high-grade histology. Human Iтmunology, 70, 1006-1009.

106. Sheu, J. J., \& Shih Ie, M. (2007). Clinical and biological significance of HLA-G expression in ovarian cancer. Seminars in Cancer Biology, 17, 436-443.

107. Rebmann, V., Regel, J., Stolke, D., \& Grosse-Wilde, H. (2003). Secretion of sHLA-G molecules in malignancies. Seminars in Cancer Biology, 13, 371-377.

108. Singer, G., Rebmann, V., Chen, Y. C., et al. (2003). HLA-G is a potential tumor marker in malignant ascites. Clinical Cancer Research, 9, 4460-4464.

109. Mach, P., Blecharz, P., Basta, P., et al. (2010). Differences in the soluble HLA-G blood serum concentration levels in patients with ovarian cancer and ovarian and deep endometriosis. American Journal of Reproductive Immunology, 63, 387-395.

110. Lin, A., Yan, W. H., Xu, H. H., et al. (2007). HLA-G expression in human ovarian carcinoma counteracts NK cell function. Annals of Oncology, 18, 1804-1809.

111. Simon, I., \& Katsaros, D. (2007). Rigault de la Longrais I, et al. B7-H4 is over-expressed in early-stage ovarian cancer and is independent of CA125 expression. Gynecologic Oncology, 106, 334-341.

112. Simon, I., Liu, Y., Krall, K. L., et al. (2007). Evaluation of the novel serum markers B7-H4, Spondin 2, and DcR3 for diagnosis and early detection of ovarian cancer. Gynecologic Oncology, 106, 112-118.

113. Simon, I., Zhuo, S., Corral, L., et al. (2006). B7-h4 is a novel membrane-bound protein and a candidate serum and tissue biomarker for ovarian cancer. Cancer Research, 66, 1570-1575.

114. Gubbels, J. A., Felder, M., Horibata, S., et al. (2010). MUC16 provides immune protection by inhibiting synapse formation between NK and ovarian tumor cells. Molecular Cancer, 9.

115. Krockenberger, M., Dombrowski, Y., Weidler, C., et al. (2008). Macrophage migration inhibitory factor contributes to the immune escape of ovarian cancer by down-regulating NKG2D. The Journal of Immunology, 180, 7338-7348.

116. Agarwal, R., Whang, D. H., Alvero, A. B., et al. (2007). Macrophage migration inhibitory factor expression in ovarian cancer. American Journal of Obstetrics and Gynecology, 196, 348 e1348 e5.

117. Sonoda, K., Miyamoto, S., Yotsumoto, F., et al. (2007). Clinical significance of RCAS1 as a biomarker of ovarian cancer. Oncology Reports, 17, 623-628.

118. McGilvray, R. W., Eagle, R. A., Rolland, P., Jafferji, I., Trowsdale, J., \& Durrant, L. G. (2010). ULBP2 and RAET1E NKG2D ligands are independent predictors of poor prognosis in ovarian cancer patients. International Journal of Cancer, 127, 1412-1420.

119. Franck, J., Longuespee, R., Wisztorski, M., et al. (2010). MALDI mass spectrometry imaging of proteins exceeding 30,000 daltons. Medical Science Monitor, 16, BR293-BR299.

120. Lemaire, R., Lucot, J. P., Collinet, P., Vinatier, D., Tabet, J. C., Salzet, M., \& Fournier, I. (2005). New developments in direct analyses by MALDI mass spectrometry for study ovarian cancer. Molecular \& Cellular Proteomics, 4, S305-S308.

121. Yang, Y., Fruh, K., Ahn, K., \& Peterson, P. A. (1995). in vivo assembly of the proteasomal complexes, implications for antigen processing. Journal of Biological Chemistry, 270, 27687-27694.

122. Kloetzel, P. M. (1998). The proteasome system: a neglected tool for improvement of novel therapeutic strategies? Gene Therapy, $5,1297-1298$.

123. Rivett, A. J., \& Gardner, R. C. (2000). Proteasome inhibitors: from in vitro uses to clinical trials. Journal of Peptide Science, 6 , 478-488.

124. Rotem-Yehudar, R., Groettrup, M., Soza, A., Kloetzel, P. M., \& Ehrlich, R. (1996). LMP-associated proteolytic activities and TAPdependent peptide transport for class $1 \mathrm{MHC}$ molecules are suppressed in cell lines transformed by the highly oncogenic adenovirus 12. The Journal of Experimental Medicine, 183, 499-514.

125. Kuckelkorn, U., Ruppert, T., Strehl, B., et al. (2002). Link between organ-specific antigen processing by $20 \mathrm{~S}$ proteasomes and CD8(+) T cell-mediated autoimmunity. The Journal of Experimental Medicine, 195, 983-990.

126. Regad, T., Saib, A., Lallemand-Breitenbach, V., Pandolfi, P. P., de The, H., \& Chelbi-Alix, M. K. (2001). PML mediates the interferon-induced antiviral state against a complex retrovirus via its association with the viral transactivator. EMBO Journal, 20, 3495-3505.

127. Delp, K., Momburg, F., Hilmes, C., Huber, C., \& Seliger, B. (2000). Functional deficiencies of components of the MHC class 
I antigen pathway in human tumors of epithelial origin. Bone Marrow Transplantation, 25(Suppl 2), S88-S95.

128. Sorem, J., Jardetzky, T. S., \& Longnecker, R. (2009). Cleavage and secretion of Epstein-Barr virus glycoprotein 42 promote membrane fusion with B lymphocytes. Journal of Virology, 83, 6664-6672.

129. Sorem, J., \& Longnecker, R. (2009). Cleavage of Epstein-Barr virus glycoprotein $\mathrm{B}$ is required for full function in cell-cell fusion with both epithelial and B cells. Journal of General Virology, 90, 591-595.

130. Pudney, V. A., Leese, A. M., Rickinson, A. B., \& Hislop, A. D. (2005). CD8+ immunodominance among Epstein-Barr virus lytic cycle antigens directly reflects the efficiency of antigen presentation in lytically infected cells. The Journal of Experimental Medicine, 201, 349-360.

131. Elg, S. A., Mayer, A. R., Carson, L. F., Twiggs, L. B., Hill, R. B., \& Ramakrishnan, S. (1997). Alpha-1 acid glycoprotein is an immunosuppressive factor found in ascites from ovaria carcinoma. Cancer, 80, 1448-1456.

132. Nosov, V., Su, F., Amneus, M., et al. (2009). Validation of serum biomarkers for detection of early-stage ovarian cancer. American Journal of Obstetrics and Gynecology, 200, 639 e1-639 e5.

133. Kim, K. D., Lim, H. Y., Lee, H. G., et al. (2005). Apolipoprotein A-I induces IL-10 and PGE2 production in human monocytes and inhibits dendritic cell differentiation and maturation. Biochemical and Biophysical Research Communications, 338, 1126-1136.

134. Liang, X., Lin, T., Sun, G., Beasley-Topliffe, L., Cavaillon, J. M., \& Warren, H. S. (2009). Hemopexin down-regulates LPSinduced proinflammatory cytokines from macrophages. Journal of Leukocyte Biology, 86, 229-235.

135. Leygue, E., Snell, L., Dotzlaw, H., et al. (1998). Expression of lumican in human breast carcinoma. Cancer Research, 58, 1348-1352.

136. Leygue, E., Snell, L., Dotzlaw, H., et al. (2000). Lumican and decorin are differentially expressed in human breast carcinoma. The Journal of Pathology, 192, 313-320.

137. Babelova, A., Moreth, K., Tsalastra-Greul, W., et al. (2009). Biglycan: A danger signal that activates the NLRP3 inflammasome via toll-like and P2X receptors. Journal of Biological Chemistry, 284(36), 24035-24048.

138. Schaefer, L., Babelova, A., Kiss, E., et al. (2005). The matrix component biglycan is proinflammatory and signals through Tolllike receptors 4 and 2 in macrophages. Journal of Clinical Investigation, 115, 2223-2233.

139. Salzet, M., Capron, A., \& Stefano, G. B. (2000). Molecular crosstalk in host-parasite relationships: schistosome- and leechhost interactions. Parasitology Today, 16, 536-540.

140. Huber, M. A., Kraut, N., \& Beug, H. (2005). Molecular requirements for epithelial-mesenchymal transition during tumor progression. Current Opinion in Cell Biology, 17, 548-558.

141. Cavallaro, U., \& Christofori, G. (2004). Cell adhesion and signalling by cadherins and Ig-CAMs in cancer. Nature Reviews. Cancer, 4, 118-132.

142. Ponnusamy, M. P., Lakshmanan, I., Jain, M., et al. (2010). MUC4 mucin-induced epithelial to mesenchymal transition: a novel mechanism for metastasis of human ovarian cancer cells. Oncogene, 29, 5741-5754.

143. Hudson, L. G., Zeineldin, R., \& Stack, M. S. (2008). Phenotypic plasticity of neoplastic ovarian epithelium: unique cadherin profiles in tumor progression. Clinical \& Experimental Metastasis, $25,643-655$.

144. Imai, T., Horiuchi, A., Wang, C., et al. (2003). Hypoxia attenuates the expression of E-cadherin via up-regulation of SNAIL in ovarian carcinoma cells. American Journal of Pathology, 163, 1437-1447.

145. Byrne, A. T., Ross, L., Holash, J., et al. (2003). Vascular endothelial growth factor-trap decreases tumor burden, inhibits ascites, and causes dramatic vascular remodeling in an ovarian cancer model. Clinical Cancer Research, 9, 5721-5728.

146. Bartlett, J. M., Langdon, S. P., Simpson, B. J., et al. (1996). The prognostic value of epidermal growth factor receptor mRNA expression in primary ovarian cancer. British Journal of Cancer, 73, 301-306.

147. Symowicz, J., Adley, B. P., Gleason, K. J., et al. (2007). Engagement of collagen-binding integrins promotes matrix metalloproteinase-9dependent E-cadherin ectodomain shedding in ovarian carcinoma cells. Cancer Research, 67, 2030-2039.

148. Ellerbroek, S. M., Halbleib, J. M., Benavidez, M., et al. (2001). Phosphatidylinositol 3-kinase activity in epidermal growth factorstimulated matrix metalloproteinase-9 production and cell surface association. Cancer Research, 61, 1855-1861.

149. Nagy, J. A., Masse, E. M., Herzberg, K. T., et al. (1995). Pathogenesis of ascites tumor growth: vascular permeability factor, vascular hyperpermeability, and ascites fluid accumulation. Cancer Research, 55, 360-368.

150. Casey, R. C., Burleson, K. M., Skubitz, K. M., et al. (2001). Beta 1-integrins regulate the formation and adhesion of ovarian carcinoma multicellular spheroids. American Journal of Pathology, 159, 2071-2080.

151. Shield, K., Riley, C., Quinn, M. A., Rice, G. E., Ackland, M. L., \& Ahmed, N. (2007). Alpha2betal integrin affects metastatic potential of ovarian carcinoma spheroids by supporting disaggregation and proteolysis. Journal of Carcinogenesis, 6, 11.

152. Moss, N. M., Barbolina, M. V., Liu, Y., Sun, L., Munshi, H. G., \& Stack, M. S. (2009). Ovarian cancer cell detachment and multicellular aggregate formation are regulated by membrane type 1 matrix metalloproteinase: a potential role in I.p. metastatic dissemination. Cancer Research, 69, 7121-7129.

153. Davidson, B., Goldberg, I., Berner, A., et al. (2001). Expression of membrane-type 1,2, and 3 matrix metalloproteinases messenger RNA in ovarian carcinoma cells in serous effusions. American Journal of Clinical Pathology, 115, 517-524.

154. Slack-Davis, J. K., Atkins, K. A., Harrer, C., Hershey, E. D., \& Conaway, M. (2009). Vascular cell adhesion molecule-1 is a regulator of ovarian cancer peritoneal metastasis. Cancer Research, 69, 1469-1476.

155. Cannistra, S. A., Kansas, G. S., Niloff, J., DeFranzo, B., Kim, Y., \& Ottensmeier, C. (1993). Binding of ovarian cancer cells to peritoneal mesothelium in vitro is partly mediated by $\mathrm{CD} 44 \mathrm{H}$. Cancer Research, 53, 3830-3838.

156. Zecchini, S., Bombardelli, L., Decio, A., et al. (2011). The adhesion molecule NCAM promotes ovarian cancer progression via FGFR signalling. EMBO Molecular Medicine, 3, 480-494.

157. Kenny, H. A., Kaur, S., Coussens, L. M., \& Lengyel, E. (2008). The initial steps of ovarian cancer cell metastasis are mediated by MMP-2 cleavage of vitronectin and fibronectin. Journal of Clinical Investigation, 118, 1367-1379.

158. Kenny, H. A., \& Lengyel, E. (2009). MMP-2 functions as an early response protein in ovarian cancer metastasis. Cell Cycle, 8 , 683-688.

159. Huang, S., Van Arsdall, M., Tedjarati, S., et al. (2002). Contributions of stromal metalloproteinase- 9 to angiogenesis and growth of human ovarian carcinoma in mice. Journal of the National Cancer Institute, 94, 1134-1142.

160. Satpathy, M., Shao, M., Emerson, R., Donner, D. B., \& Matei, D. (2009). Tissue transglutaminase regulates matrix metalloproteinase2 in ovarian cancer by modulating cAMP-response element-binding protein activity. Journal of Biological Chemistry, 284, 1539015399.

161. Dorn, J., Harbeck, N., Kates, R., et al. Impact of expression differences of kallikrein-related peptidases and of uPA and PAI1 between primary tumor and omentum metastasis in advanced ovarian cancer. Annals of Oncology, 22, 877-883. 
162. Nishida, N., Yano, H., Komai, K., Nishida, T., Kamura, T., \& Kojiro, M. (2004). Vascular endothelial growth factor C and vascular endothelial growth factor receptor 2 are related closely to the prognosis of patients with ovarian carcinoma. Cancer, 101, 1364-1374.

163. Zhu, M., Fejzo, M. S., Anderson, L., et al. (2011). Periostin promotes ovarian cancer angiogenesis and metastasis. Gynecologic Oncology, 119, 337-344.

164. Popple, A., Durrant, L. G., Spendlove, I., et al. (2012). The chemokine, CXCL12, is an independent predictor of poor survival in ovarian cancer. British Journal of Cancer, 106, 1306-1313.

165. Johnson, E. L., Singh, R., Singh, S., et al. (2010). CCL25-CCR9 interaction modulates ovarian cancer cell migration, metalloproteinase expression, and invasion. World Journal of Surgical Oncology, 8, 62.

166. Nieman, K.M., Kenny, H.A., Penicka, C.V., et al. Adipocytes promote ovarian cancer metastasis and provide energy for rapid tumor growth. Natural Medicines, 17, 1498-1503.

167. Zhang, Y., Tang, H., Cai, J., et al. (2011). Ovarian cancerassociated fibroblasts contribute to epithelial ovarian carcinoma metastasis by promoting angiogenesis, lymphangiogenesis and tumor cell invasion. Cancer Letters, 303, 47-55.

168. He, Y., Wu, X., Liu, X., Yan, G., \& Xu, C. (2010). LC-MS/MS analysis of ovarian cancer metastasis-related proteins using a nude mouse model: 14-3-3 zeta as a candidate biomarker. Journal of Proteome Research, 9, 6180-6190.

169. Yaffe, M. B., Rittinger, K., Volinia, S., et al. (1997). The structural basis for 14-3-3:phosphopeptide binding specificity. Cell, 91, 961-971.

170. Ogihara, T., Isobe, T., Ichimura, T., et al. (1997). 14-3-3 protein binds to insulin receptor substrate-1, one of the binding sites of which is in the phosphotyrosine binding domain. Journal of Biological Chemistry, 272, 25267-25274.

171. Deakin, N. O., Bass, M. D., Warwood, S., et al. (2009). An integrin-alpha4-14-3-3zeta-paxillin ternary complex mediates localised Cdc42 activity and accelerates cell migration. Journal of Cell Science, 122, 1654-1664.

172. Ravi, D., Chen, Y., Karia, B., et al. 14-3-3 sigma expression effects $\mathrm{G} 2 / \mathrm{M}$ response to oxygen and correlates with ovarian cancer metastasis. PLoS One, 6, e15864.

173. Fong, M.Y., McDunn, J., Kakar, S.S. Identification of metabolites in the normal ovary and their transformation in primary and metastatic ovarian cancer. PLoS One, 6, e19963.

174. Ozols, R. F., Bookman, M. A., Connolly, D. C., et al. (2004). Focus on epithelial ovarian cancer. Cancer Cell, 5, 19-24.

175. Bast, R. C., Jr., Klug, T. L., St John, E., et al. (1983). A radioimmunoassay using a monoclonal antibody to monitor the course of epithelial ovarian cancer. The New England Journal of Medicine, 309, 883-887.

176. Nustad, K., Bast, R. C., Jr., Brien, T. J., et al. (1996). Specificity and affinity of 26 monoclonal antibodies against the CA 125 antigen: first report from the ISOBM TD-1 workshop. International Society for Oncodevelopmental Biology and Medicine. Tumour Biology, 17, 196-219.

177. Ripley, D., Shoup, B., Majewski, A., \& Chegini, N. (2004). Differential expression of interleukins IL-13 and IL-15 in normal ovarian tissue and ovarian carcinomas. Gynecologic Oncology, 92, 761-768.

178. Kioi, M., Kawakami, M., Shimamura, T., Husain, S. R., \& Puri, R. K. (2006). Interleukin-13 receptor alpha2 chain: a potential biomarker and molecular target for ovarian cancer therapy. Cancer, 107, 1407-1418.

179. Hellstrom, I., Raycraft, J., Hayden-Ledbetter, M., et al. (2003). The HE4 (WFDC2) protein is a biomarker for ovarian carcinoma. Cancer Research, 63, 3695-3700.
180. Suzuki, M., Ohwada, M., Aida, I., Tamada, T., Hanamura, T., \& Nagatomo, M. (1993). Macrophage colony-stimulating factor as a tumor marker for epithelial ovarian cancer. Obstetrics and Gynecology, 82, 946-950.

181. Xu, F. J., Ramakrishnan, S., Daly, L., et al. (1991). Increased serum levels of macrophage colony-stimulating factor in ovarian cancer. American Journal of Obstetrics and Gynecology, 165, $1356-1362$.

182. Chechlinska, M., Kaminska, J., Markowska, J., Kramar, A., \& Steffen, J. (2007). Peritoneal fluid cytokines and the differential diagnosis of benign and malignant ovarian tumors and residual/ recurrent disease examination. The International Journal of Biological Markers, 22, 172-180.

183. Xu, Y., Shen, Z., Wiper, D. W., et al. (1998). Lysophosphatidic acid as a potential biomarker for ovarian and other gynecologic cancers. Journal of the American Medical Association, 280, 719 723.

184. Woolas, R. P., Conaway, M. R., Xu, F., et al. (1995). Combinations of multiple serum markers are superior to individual assays for discriminating malignant from benign pelvic masses. Gynecologic Oncology, 59, 111-116.

185. Zhang, Z., Barnhill, S. D., Zhang, H., et al. (1999). Combination of multiple serum markers using an artificial neural network to improve specificity in discriminating malignant from benign pelvic masses. Gynecologic Oncology, 73, 56-61.

186. Visintin, I., Feng, Z., Longton, G., et al. (2008). Diagnostic markers for early detection of ovarian cancer. Clinical Cancer Research, 14, 1065-1072.

187. Moore, R. G., \& Maclaughlan, S. (2010). Current clinical use of biomarkers for epithelial ovarian cancer. Current Opinion in Oncology, 22, 492-497.

188. Kurman, R.J., McConnell, T.G. Characterization and comparison of precursors of ovarian and endometrial carcinoma: parts I and II. International Journal of Surgical Pathology, 18, 181S-189S.

189. Kurman, R. J., \& McConnell, T. G. (2010). Precursors of endometrial and ovarian carcinoma. Virchows Archiv, 456, 1-12.

190. Kurman, R. J., \& Shih Ie, M. (2010). The origin and pathogenesis of epithelial ovarian cancer: a proposed unifying theory. The American Journal of Surgical Pathology, 34, 433-443.

191. Longuespé, R.B., CCastellier, C., Jacquet, E., Desmons, A., Kerdraon, O., Vinatier, D., Day, R., Fournier, I., Salzet, M. The C-terminal fragment of the immunoproteasome PA28S (Reg Alpha) as an early diagnosis and tumor-relapse biomarker: evidence from mass spectrometry profiling. Histochem and Cell Biochem 2012; in press: D.O.I. 10.1007/s00418-012-0953-0.

192. Tinelli, A., Vergara, D., Martignago, R., et al. (2007). Ovarian cancer biomarkers: a focus on genomic and proteomic findings. Current Genomics, 8, 335-342.

193. Diefenbach, C. S., Soslow, R. A., Iasonos, A., et al. (2006). Lysophosphatidic acid acyltransferase-beta (LPAAT-beta) is highly expressed in advanced ovarian cancer and is associated with aggressive histology and poor survival. Cancer, 107, 1511-1519.

194. Kim, H., Watkinson, J., Varadan, V., \& Anastassiou, D. (2010). Multi-cancer computational analysis reveals invasion-associated variant of desmoplastic reaction involving INHBA, THBS2 and COL11A1. BMC Medical Genomics, 3, 51.

195. Oikonomopoulou, K., Batruch, I., Smith, C. R., Soosaipillai, A., Diamandis, E. P., \& Hollenberg, M. D. (2010). Functional proteomics of kallikrein-related peptidases in ovarian cancer ascites fluid. Biological Chemistry, 391, 381-390.

196. Ahmed, A. S., Dew, T., Lawton, F. G., et al. (2007). Tumour M2$\mathrm{PK}$ as a predictor of surgical outcome in ovarian cancer, a prospective cohort study. European Journal of Gynaecological Oncology, 28, 103-108.

197. Ayhan, A., Ertunc, D., \& Tok, E. C. (2005). Expression of the c-Met in advanced epithelial ovarian cancer and its 
prognostic significance. International Journal of Gynecological Cancer, 15, 618-623.

198. Tang, M.K., Zhou, H.Y., Yam, J.W., Wong, A.S. c-Met overexpression contributes to the acquired apoptotic resistance of nonadherent ovarian cancer cells through a cross talk mediated by phosphatidylinositol 3-kinase and extracellular signalregulated kinase 1/2. Neoplasia, 12, 128-138.

199. Zhou, H. Y., Pon, Y. L., \& Wong, A. S. (2008). HGF/MET signaling in ovarian cancer. Current Molecular Medicine, 8, 469-480.

200. Coffelt, S. B., Marini, F. C., Watson, K., et al. (2009). The proinflammatory peptide LL-37 promotes ovarian tumor progression through recruitment of multipotent mesenchymal stromal cells. Proceedings of the National Academy of Sciences of the United States of America, 106, 3806-3811.

201. Zohny, S. F., \& Fayed, S. T. (2010). Clinical utility of circulating matrix metalloproteinase-7 (MMP-7), CC chemokine ligand 18 (CCL18) and CC chemokine ligand 11 (CCL11) as markers for diagnosis of epithelial ovarian cancer. Medical Oncology, 27, 1246-1253.

202. Landen, C. N., Kinch, M. S., \& Sood, A. K. (2005). EphA2 as a target for ovarian cancer therapy. Expert Opinion on Therapeutic Targets, 9, 1179-1187.

203. Lu, C., Shahzad, M. M., Wang, H., et al. (2008). EphA2 overexpression promotes ovarian cancer growth. Cancer Biology \& Therapy, 7, 1098-1103.

204. Thaker, P. H., Deavers, M., Celestino, J., et al. (2004). EphA2 expression is associated with aggressive features in ovarian carcinoma. Clinical Cancer Research, 10, 5145-5150.

205. Kobel, M., Kalloger, S. E., Boyd, N., et al. (2008). Ovarian carcinoma subtypes are different diseases: implications for biomarker studies. PLoS Medicine, 5, e232.

206. Lim, R., Ahmed, N., Borregaard, N., et al. (2007). Neutrophil gelatinase-associated lipocalin (NGAL) an early-screening biomarker for ovarian cancer: NGAL is associated with epidermal growth factor-induced epithelio-mesenchymal transition. International Journal of Cancer, 120, 2426-2434.

207. Bjorge, L., Hakulinen, J., Vintermyr, O. K., et al. (2005). Ascitic complement system in ovarian cancer. British Journal of Cancer, 92, 895-905.

208. Fischer, D. C., Noack, K., Runnebaum, I. B., et al. (2004). Expression of splicing factors in human ovarian cancer. Oncology Reports, 11, 1085-1090.
209. Surowiak, P., Materna, V., Maciejczyk, A., et al. (2006). CD46 expression is indicative of shorter revival-free survival for ovarian cancer patients. Anticancer Research, 26, 49434948.

210. Rousseau, J., Tetu, B., Caron, D., et al. (2002). RCAS1 is associated with ductal breast cancer progression. Biochemical and Biophysical Research Communications, 293, 1544-1549.

211. Tilli, T. M., Franco, V. F., Robbs, B. K., et al. (2011). Osteopontin-c splicing isoform contributes to ovarian cancer progression. Molecular Cancer Research, 9(3), 280-293.

212. Yan, X. D., \& Pan, L. Y. (2006). Proteomic analysis of human ovarian cancer cell lines and their platinum-resistant clones. Zhonghua Fu Chan Ke Za Zhi, 41, 584-587.

213. Yan, X. D., Pan, L. Y., Yuan, Y., Lang, J. H., \& Mao, N. (2007). Identification of platinum-resistance associated proteins through proteomic analysis of human ovarian cancer cells and their platinum-resistant sublines. Journal of Proteome Research, 6, $772-780$.

214. Nishimura, S., Tsuda, H., Kataoka, F., et al. (2011). Overexpression of cofilin 1 can predict progression-free survival in patients with epithelial ovarian cancer receiving standard therapy. Human Pathology, 42(4), 516-521.

215. Jones, M. B., Krutzsch, H., Shu, H., et al. (2002). Proteomic analysis and identification of new biomarkers and therapeutic targets for invasive ovarian cancer. Proteomics, 2, 76-84.

216. Alper, T., Kahraman, H., Cetinkaya, M. B., et al. (2004). Serum leptin and body composition in polycystic ovarian syndrome. Annals of Saudi Medicine, 24, 9-12.

217. Erturk, E., \& Tuncel, E. (2003). Polycystic ovarian disease and serum leptin levels? Fertility and Sterility, 80, 1068-1069. author reply 9-70.

218. Qian, B., Katsaros, D., Lu, L., et al. (2011). IGF-II promoter specific methylation and expression in epithelial ovarian cancer and their associations with disease characteristics. Oncology Reports, 25, 203-213.

219. Park, E. K., Johnson, A. R., Yates, D. H., \& Thomas, P. S. (2011). Evaluation of ovarian cancer biomarkers in subjects with benign asbestos-related pleural diseases. Clinical Chemistry and Laboratory Medicine, 49, 147-150.

220. Bengtsson, S., Krogh, M., Szigyarto, C. A., et al. (2007). Largescale proteomics analysis of human ovarian cancer for biomarkers. Journal of Proteome Research, 6, 1440-1450. 